\title{
Research on blasting vibration effect and time-frequency characteristics of vibration signals in a road corridor at xianning nuclear power station
}

\author{
Yongqing Zeng ${ }^{1}$, Haibo $\mathrm{Li}^{2}$, Xiang Xia ${ }^{3}$, Junru $\mathrm{Li}^{4}$, Zhiwei $\mathrm{Li}^{5}$, Xiaohong $\mathrm{Liu}^{6}$ \\ ${ }^{1,6}$ College of Civil Engineering and Architecture, Hunan Institute of Science and Technology, \\ Yueyang, 414000, China \\ ${ }^{2,3,4,5}$ State Key Laboratory of Geomechanics and Geotechnical Engineering, Institute of Rock and Soil \\ Mechanics, Chinese Academy of Sciences, Wuhan, 430071, China \\ ${ }^{6}$ Corresponding author

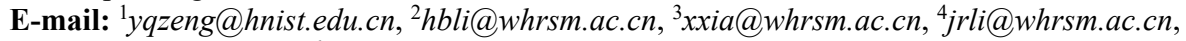 \\ 52227638024@qq.com,611991491@hnist.edu.cn
}

Received 21 December 2020; received in revised form 18 March 2021; accepted 1 April 2021 DOI https://doi.org/10.21595/jve.2021.21848

Check for updates

Copyright $(C) 2021$ Yongqing Zeng, et al. This is an open access article distributed under the Creative Commons Attribution License, which permits unrestricted use, distribution, and reproduction in any medium, provided the original work is properly cited.

\begin{abstract}
Drill and blast is a major method for foundation excavation in nuclear power plant engineering. For transporting heavy components to engineering construction, the blast-induced vibration of foundation excavation in a road corridor may has a great influence on new pouring mass concrete and surrounding bedrock in Xianning Nuclear Power Station, which will affect the safety of the engineering construction. So it is necessary to monitor the process of blasting excavation and put forward effective control measures on blasting vibration effect, in which the peak particle velocity (PPV) attenuation law are investigated through regression analysis of practical field data by Duvall empirical formula and the time-frequency characteristics was analyzed by wavelet transform and wavelet package decomposition. By analyzing the velocity amplitude and power spectrum density amplitude of wavelet components, it shows the blast energy of original vibration signal is mainly within the frequency below $250 \mathrm{~Hz}$ and has three sub-band which varies from $10 \mathrm{~Hz}$ to $30 \mathrm{~Hz}$, from $40 \mathrm{~Hz}$ to $70 \mathrm{~Hz}$ and from $75 \mathrm{~Hz}$ to $125 \mathrm{~Hz}$, respectively. Wavelet packet analysis indicates the energy of the signal in $0-125 \mathrm{~Hz}$ accounts for $94.25 \%$ of the total signal. At the same time, for the sake of ensuring the safety of road corridor, Chinese admissibility standards (GB6722-2014) of blasting-induced vibration and the constants obtained from the regression were used to establish the maximum explosive charge per delay for an acceptable ground vibration level that would not cause damage for new pouring mass concrete and bedrock in road corridor. The safety criteria of particle vibration velocity for new pouring mass concrete and bedrock in road corridor could be both set as $5 \mathrm{~cm} / \mathrm{s}$, which show the remarkable effect on blasting damage control of the new pouring mass concrete and surrounding bedrock, the results demonstrate that controlling maximum explosive charge per delay methodology can be commendably applied to road corridor to control blasting-induced vibration effects.
\end{abstract}

Keywords: blasting vibration effect, time-frequency characteristics, road corridor, wavelet analysis, safety threshold.

\section{Introduction}

China is in the stage of rapid economic development and continuous infrastructure construction, blasting engineering plays an increasingly prominent role in highway excavation, hydropower construction, underground space development and other fields $[1,2]$; however, a series of negative effects caused by blasting have attracted widespread attention. The stress wave and explosion gases will not only reduce the joint strength and aggrandize the permeability of rock, but also cause building crack, landslide, tunnel collapse and many other hazards [3, 4]; therefore, it is necessary to control blasting vibration effect for ensuring the blasting damage of rock mass and building is within safety criterion range $[5,6]$. In the construction of nuclear power 
project, in order to speed up the construction progress, the blasting excavation and the concrete pouring near the adjacent parts are often simultaneously executed, so there is a general problem that the impact of blasting vibration may damage the new pouring large volume concrete. The strength of concrete at different ages is different, for early age concrete with low strength, excessive blasting vibration will cause cracks in cement mortar or cracks at the junction of aggregate and slurry, even forming penetrating cracks, which will affect the later concrete strength [7]. According to the design requirements of Xianning nuclear power station, it is necessary to carry out foundation excavation blasting of road corridor for transporting heavy components to engineering construction, the stress wave and high pressure gas in the process of blasting excavation may cause different degrees damage to the new pouring mass concrete and surrounding rock mass, which will affect the safety of engineering construction, so it is necessary to monitor the process of blasting excavation and put forward effective control measures on blasting vibration effect for the safety of near new pouring large volume concrete and surrounding rock mass in blasting field.

Numerous researches on the blasting vibration effect of different engineering backgrounds such as highway tunnel, urban subway tunnel, nuclear power station, hydropower station and coal mining have been carried out using field measurement and theoretical analysis. Sun et al. [8] and Deng et al. [9] evaluated the safety distance and the causes of house cracking for buildings near the blasting area at highway, in addition, based on the excavation of Jiahua tunnel, the damage status of ground buildings in the blast vibration area was qualitatively analyzed by using the method of fault tree analysis in safety system engineering [10]. Li et al. [11] and Zeng et al. [12] studied the characteristics of wave propagation and blast-induced damage to rock mass by site seismic survey and sonic wave test; the relationship between peak particle velocity at $30 \mathrm{~m}$ away from the charge hole and the damage depth of rock mass is established, a simple method based on safety threshold of vibration velocity for rock mass to restrict the damage depth of rock mass under blasting excavation is presented. In order to assess damage controlling of blast vibrations considering rock properties of underwater blasting, Li et al. [13] proposed a novel model for predicting peak particle velocity (PPV) considering the effects of geological factor, rock properties and engineering category on the attenuation of ground vibrations and frequency, the novel predictor, formed by adding the depth ratio of the water to the scaled distance law suggested by Duvall and Fogelson, is verified by the agreement of measurement data with a correlation coefficient of $92 \%$. Nateghi $[14,15]$ described blasting-induced ground vibration level of underground and surface concrete structures and analyzed the effects of different rock formations, different detonators and explosives during the construction of upper Gotvand dam. Li [16] proposed a method to predict the time history of blast vibrations on high slopes, the spectral prediction and control of blast vibrations during the excavation of high dam abutment slopes with millisecond-delay blasting is presented in the Xiluodu hydropower project. Qiu [17] proposed a new blasting pattern using short-delay intervals in order to improve rock breaking and control blast induced vibrations in cutting blasting with single free surface in underground mines. Faramarzi [18] achieved simultaneous investigation of blast induced ground vibration and airblast effects on safety level of structures and human in surface blasting at Sungun Copper Mine, Iran. Ak $[19,20]$ examined the impacts of discontinuity frequency parameter on the propagation of blast-induced ground vibrations and analyzed the results of ground vibration measurement to predict peak particle velocity and to determine the slope attenuation curve on the blasting benches at a quarry mine in Turkey, the prediction graphics of maximum charge weight per delay versus distance for different damage criteria was proposed in order not to damage to nearby structures. Effect of bedding plane on prediction blast-induced ground vibration in open pit coal mines was researched, PPV attenuates more rapidly within the steeply dipping multiple bed rock masses down and up dip compared to along the strike [21]. Shin [22] attempts to identify the effect of blast-induced vibration on the adjacent tunnels in soft rock, a guideline for evaluating the blast protection zone is proposed based on a parametric study on blast location, tunnel depth, and the amount of explosives. Yu [23] evaluated influence of vibrations generated by blasting construction 
on an existing tunnel in soft soils by field monitoring and finite element software ABAQUS. Similarly, Xia [24] presented a case study on rock damage prediction and control method for underground tunnels subjected to adjacent excavation blasting, the effects of tunnel blast excavation on the surrounding rock mass and the lining systems of adjacent existing tunnels are comprehensively studied for the Damaoshan highway tunnel project. Gou [25] assessed attenuation of blast-induced vibrations derived from an underground mine, the influence of blasting design, propagating medium and its mechanical parameters on PPV and frequency attenuation law were also carefully investigated. Singh P. K. [26] and Roy [27] studied blast vibration effects in an underground mine caused by open-pit mining, ground vibration recorded at roof, pillar and floor were analyzed separately and the threshold value of vibration for the safety of underground workings has been determined based on the Rock Mass Rating values of the roof rock, at the same time, accordingly blast designs have been optimized. In order to assess the influence of underground mining blasting on the stability of open pit slopes and control the potential risk, Jiang and Zhou [28] investigated a mathematical model to describe the attenuation of blasting vibration on open pit slopes subjected to underground mining blasting in Daye Iron Mine, the PPV predicting model for high slopes at different elevations was proposed based on the numerical simulations of underground mining blasting.

As for the time-frequency characteristic and safety standards of blasting vibration signal, Li et al. [29] analyzed a practical blasting vibration signal by means of wavelet transform (WT) and Hilbert-Huang Transform (HHT), the presented results show that both WT and HHT are efficient ways for analyzing and processing non-stationary signals, and can draw main characteristic information from signals as well as carry out wave filtration and noise elimination. The influence of the blasting vibration on the structure was assessed based on the relation between characteristic frequency of blasting seismic signals on different frequency bands and natural frequency of controlled structure by means of the wavelet packet analysis, a practical engineering example proved that the wavelet packet analysis method was more effective than the safety-judging standard of single intensity factor for blasting vibration [30]. Zhong et al. [31] discussed the dynamic response of structures and the effect of inherent characteristics of controlled structures to blasting vibration, frequency band response coefficients and multi-factor blasting vibration safety criteria for controlled structures by blasting vibration have been obtained. Besides, energy distributions for different frequency bands of blast vibration signal are obtained and the characteristics of energy distributions for blast vibration signal measured under different explosion parameters (the maximum explosive weight per delay, the distance of blast source to measuring point and the section number of millisecond detonator) are analyzed [32]. Zhao [33] study the time-frequency characteristics of blasting vibration signals measured in milliseconds by applying a combination of reassigned smoothed pseudo Wigner-Ville distribution (RSPWVD) and wavelet at an open pit of the Jinduicheng Mine, the effect of milliseconds intervals on time-frequency characteristics of blasting vibration signals is significant. Han and Ma [34] studied the impacts of blasting vibration on surrounding rock and existing roadway structure by taking driving blasting in coal mine rock roadway as engineering background, in which wavelet packet method is used to decompose blasting vibration signals and to draw energy distribution features in different frequency bands. The accurate identification of delay time in millisecond blasting plays an important role in the optimization of blasting design and reduction of vibration effect, Shi et al. [35] compared the capability of the empirical mode decomposition (EMD) method with the instantaneous energy method based on Hilbert-Huang transform (HHT) in identifying the delay time of short millisecond blasting under precise initiation, it was found that the instantaneous energy method was adaptable to millisecond blasting with delay time longer than half of the energy peak period. In order to ensure the safety of mining, Li [36] studied the wave characteristics of natural mineral earthquake and blast in a coal mine based on the Hilbert-Huang transform (HHT) method; the dominant frequency of natural mineral earthquake wave is $20 \mathrm{~Hz}$, however, the blast wave frequency is relatively complex and its dominant frequency is $140 \mathrm{~Hz}$. Lu et al. $[37,38]$ introduced the safety standards of blast vibrations and the results of blast vibration 
measurements during bedrock excavations in Three Gorge Project and discussed several important problems related to the safety standards; the domestic safety criteria of blasting vibration and permitted standard of blasting velocity for high rock slope, underground caverns, foundation rock mass and early-aged concrete adopted in field of hydropower engineering are presented. Blasting excavation in a tunnel passing beneath an airport is quite rare at home and abroad, Lu et al. [39] carried out monitor vibration and investigated effect of excavation blasting by the dynamic finite element program LS-DYNA in an under-cross tunnel on airport runway; the numerical results showed that the airport runway was affected little and an existed cave could amplify the amplitude of blasting vibration to an extent, in addition, the safety threshold for the airport runway induced by blasting vibration was obtained.

For transporting heavy components to engineering construction, the blast-induced vibration of foundation excavation in a road corridor may has a great influence on new pouring mass concrete and surrounding bedrock in Xianning Nuclear Power Station, which will affect the safety of the engineering construction; the study on peak particle velocity (PPV) attenuation law and time-frequency characteristics of blasting vibration signal is of great importance to control vibrations induced by bench blasting. In order to reduce the damage extent to new pouring mass concrete and surrounding rock mass during the foundation blasting excavation of the road corridor, the peak particle velocity (PPV) attenuation law of blasting vibration signal has been studied through regression analysis of practical test data by Duvall empirical formula and the time-frequency characteristics of blasting vibration signal was analyzed by wavelet transform and wavelet packet transform. Furthermore, some feasible measures to mitigate the negative effects of blasting induced vibrations is given, Chinese admissibility standards (GB6722-2014) of blasting induced vibration and the constants obtained from the regression were used to establish the maximum explosive charge per delay for an acceptable ground vibration level that would not cause damage for new pouring mass concrete and bedrock in road corridor.

\section{Theory}

\subsection{Characteristics of wave propagation}

Base on wave theory and elasticity theory, when rock mass vibrates by reason of disturbance in the case of plane waves, the rock mass stress $\sigma$ for blasting can be obtained as follow [40]:

$\sigma=E \varepsilon$
$\varepsilon=\frac{v}{c_{p}}$,

where $E$ is elastic modulus, $\varepsilon$ is strain and $v, c_{p}$ is particle vibration velocity, propagation speed of vibration wave, respectively.

Combine Eq. (2) with Eq. (1), it show that:

$\sigma=\frac{E v}{c_{p}}$

We can find that the rock mass stress for blasting is proportional to particle vibration velocity; the particle vibration velocity is an important physical quantity, which can reflect the blast-induced rock mass damage, the measurement of particle vibration velocity is more convenient than the direct measurement of rock mass damage.

In general, most predictor equations of the ground vibration velocity are developed based on: (1) the maximum explosive weight per delay, $Q$, and (2) the distance between the monitoring point and blasting point, $R$. Several common empirical relationships have been suggested to describe the attenuation of blast-induced ground vibration, such as Eqs. (4)-(8) obtained by Duvall and 
Fogelson [41], Langefors and Kihlstrom [42], IS 6922 [43], Pal Roy [44], and GB6722-2014 [45], respectively:

$$
\begin{aligned}
& \mathrm{PPV}=K(S D)^{-\alpha}=K\left(R / Q^{1 / 2}\right)^{-\alpha}, \\
& \mathrm{PPV}=K\left(R^{2 / 3} / Q\right)^{-\alpha / 2}, \\
& \mathrm{PPV}=K\left(R / Q^{2 / 3}\right)^{-\alpha}, \\
& \mathrm{PPV}=n+K\left(R / Q^{1 / 3}\right)^{-1}, \\
& \mathrm{PPV}=K\left(R / Q^{1 / 3}\right)^{-\alpha},
\end{aligned}
$$

where PPV stands for the peak particle velocity at the target point, according to United States Bureau of Mines (USBM), the attenuation Eq. (4) is used most widely to study the attenuation of blast vibration [46-48], the Duvall Formula points out [41]: $Q$ is the maximum explosive weight per delay $(\mathrm{kg}), R$ is the distance between the blasting source and the measurement point $(\mathrm{m})$, $S D=R / Q^{1 / 2}$ is the scaled distance $\left(\mathrm{m} / \mathrm{kg}^{1 / 2}\right), K$ is the blasting design and field geology coefficient, and $a$ is the attenuation coefficient.

\subsection{Wavelet transform and wavelet packet transform}

Wavelet analysis is a kind of time and frequency analysis method which implement discrete transform of signal in time domain and spectrum analysis in frequency domain, it has a good localization in both time and frequency domain, which can solve the contradiction between time and frequency resolution. For the low frequency components of the signal, the wide time window can make the resolution in time domain is low and the resolution in frequency domain is high; For the high frequency components of the signal, the narrow time window can make the resolution in time domain is high and the resolution in frequency domain is low; It has many advantages and is widely used in the analysis of blasting vibration signal [40, 49].

$R$ denotes the set of real numbers. $L^{2}(R)$ denotes the vectors space of measurable, square integrable one- dimensional functions $\phi(t)$.

Supposing $\phi(t) \in L^{2}(R)$ and Fourier transform of $\phi(t)$ is $\hat{\phi}(\omega)$, if $\hat{\phi}(\omega)$ satisfy:

$C_{\phi}=\int_{R} \frac{|\hat{\phi}(\omega)|^{2}}{\omega} d \omega<\infty$,

then $\phi(t)$ is called a basis wavelet function or mother wavelet function, a set of wavelet can be obtained through the shift and scale of $\phi(t)$.

For the continuous case, the wavelet sequence is:

$\phi_{a, b}(t)=|a|^{-\frac{1}{2}} \phi((t-b) / a), \quad a, b \in R, \quad a \neq 0$,

where $a$ is scale factor, $b$ is shift factor.

For the discrete case, the wavelet sequence is:

$\phi_{j, k}(t)=2^{-j / 2} \phi\left(2^{-j} t-k\right)$,

where scale factor $a$ is taken as $a=2^{j}$, shift factor $b$ is taken as $b=2^{j} k(j, k \in Z)$.

The continuous wavelet transform of any function $f(t) \in L^{2}(R)$ is:

$W_{f}(a, b)=\left\langle f, \phi_{a, b}\right\rangle=|a|^{-\frac{1}{2}} \int_{R} f(t) \overline{\left(\frac{(t-b)}{a}\right)} d t$ 
where $\left\langle f, \phi_{a, b}\right\rangle$ denotes the inner product between $f(t)$ and $\phi_{a, b}(t) ; \overline{\phi((t-b) / a)}$ is conjugate function of $\phi((t-b) / a)$.

The continuous wavelet inverse transform is:

$f(t)=\frac{1}{C_{\phi}} \int_{R^{+}} \int_{R} \frac{1}{a^{2}} W_{f}(a, b) \phi\left(\frac{(t-b)}{a}\right) d a d b$.

The discrete wavelet transform (DWT) coefficient corresponding to function $f(t)$ and its reconstruction formula are:

$$
\begin{aligned}
& C_{j, k}=\int_{-\infty}^{\infty} f(t) \overline{\phi_{j, k}(t)} d t, \\
& f(t)=C \sum_{-\infty}^{\infty} \sum_{-\infty}^{\infty} C_{j, k} \phi_{j, k}(t),
\end{aligned}
$$

where $C$ is a constant of not related to the signal.

The frequency band of the signal obtained by the wavelet analysis is divided in equal interval. If the frequency range of the analyzed signal is $(0, W)$, then it is divided into two parts of low frequency al $(0, W / 2)$ and high frequency $d_{1}(W / 2, W)$ after one layer decomposition. The second layer wavelet decomposition is further decompose the low-frequency part a1 $(0, W / 2)$ of the first layer decomposition to two parts of low frequency a2 $(0, W / 4)$ and high frequency $d_{2}$ $(W / 4, W / 2)$; in this way, the result of wavelet decomposition of $N$ layer can be gained by decomposing $N$ times (scale $N$ ). The 3-layer discrete wavelet decomposition tree on vibration signal is illustrated in Fig. 1.

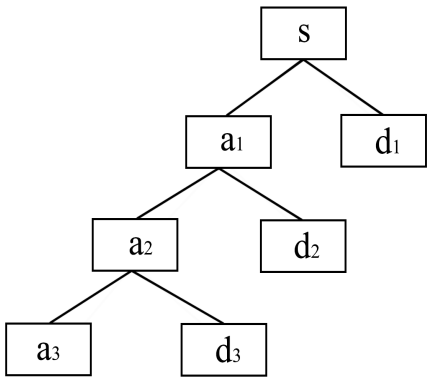

Fig. 1. 3-layer discrete wavelet decomposition tree on vibration signal

In view of the phenomenon of wavelet transform only can decompose the sub band of low frequency signal and no longer decompose the sub band of high frequency signal in the process of wavelet analysis which results in its frequency resolution decrease with the increase of frequency of signal, Wickerhauser and Coifman put forward the concept of wavelet packet decomposition and made the strict derivation mathematically [49]. The basic idea of wavelet packet transform is that the high frequency part which is not decomposed in wavelet transform is also decomposed into high frequency and low frequency parts, and the similar multi-layer partition is carried out in sequence, it can adaptively select the corresponding frequency band matching the signal frequency band according to the signal being analyzed.

The algorithm of wavelet package decomposition can be expressed as [50]: 


$$
\left\{\begin{array}{l}
d_{i+1,2 j}(k)=\sum_{l \in Z} h_{l-2 k} d_{i, j}(l), \\
d_{i+1,2 j+1}(k)=\sum_{l \in Z} h_{l-2 k} d_{i, j}(l),
\end{array}\right.
$$

where $i$ is the number of decomposition layer, $j \in\left\{0,1,2, \ldots, 2^{i}-1\right\}$ denotes the index of nodes in the $i$ th layer, $d_{i, j}$ denotes the coefficient sequence of the $j$ th node in the $i$ th layer, $d_{0,0}$ is the received signal, and $h_{l-2 k}$ and $g_{l-2 k}$ are a low-pass filter and a high-pass filter, respectively, obtained from a pair of conjugate mirror filters. The wavelet packet decomposition tree up to decomposition layer 3 is demonstrated in Fig. 2.

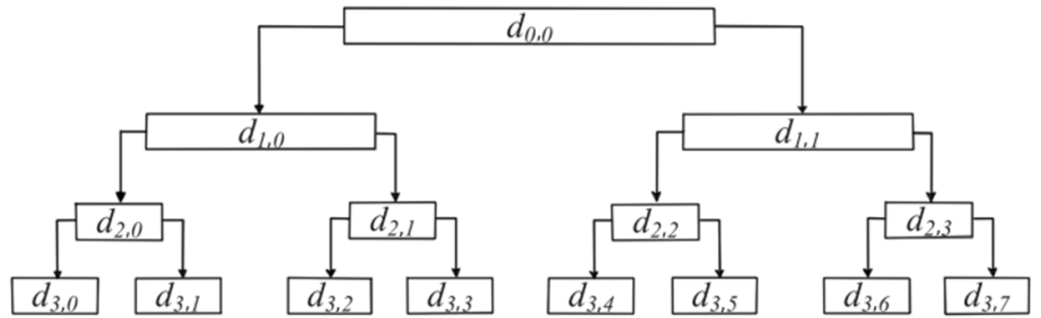

Fig. 2. 3-layer wavelet package decomposition tree on vibration signal

When the signal is analyzed in the wavelet packet analysis, the depth of the wavelet packet decomposition must be determined first. If the sampling frequency of the blasting vibration signal $s(t)$ is $2 f$, the Nyquist frequency is $f$ according to the Shannon sampling theorem; the wavelet packet decomposition is carried out at $i$ decomposition layer, total $j=2^{i}$ sub band can be obtained and the frequency width of each sub-band is $f / 2^{i}$, the energy of each frequency band signal can be obtained by reconstructing the wavelet packet decomposition coefficient and extracting each band range signal from original signal. $s(t)$ can be expressed as [34]:

$\mathrm{s}(t)=\sum_{j=0}^{2^{i}-1} s_{i, j}=s_{i, 0}+s_{i, 1}+s_{i, 2}+\cdots+s_{i, 2^{i}-1}$,

where $s_{i, j}$ denotes the reconstruction signal of the node $(i, j)$ in the $i$ th layer of wavelet packet and $j=0,1,2, \ldots, 2^{i}-1$.

In the wavelet packet energy spectrum, the square sum of the signal in each sub frequency band can be selected as the symbol of the energy, the energy of the $j$ th node in layer $i$ can be defined as:

$E_{i, j}=\int\left|s_{i, j}(t)\right|^{2} d t=\sum_{k=1}^{m}\left|x_{j, k}\right|^{2}$,

where $x_{i, j}$ is the discrete point amplitude of reconstructed signal $s_{i, j}\left(j=0,1,2, \ldots, 2^{i}-1 ; k=1\right.$, $2, \ldots, m, m$ is the number of discrete sampling points).

The total energy $E_{0}$ of blasting vibration signal $s(t)$ can be expressed as:

$E_{0}=\sum_{j=0}^{2^{i}-1} E_{i, j}$ 
The ratio of the energy of each sub frequency band to the total energy of blasting vibration signal is expressed as:

$$
I_{i, j}=\frac{E_{i, j}}{E_{0}} \times 100 \%
$$

\subsection{Safety criterion of blasting vibration effect}

The rock mass failure in the near area and middle area of the blasting source is mainly caused by explosion shock wave and stress wave, respectively. Usually, the stress wave theory is used to determine the safety criterion of bedrock fracture for blasting vibration. According to the variation form of Eq. (3), it show that:

$$
[\mathrm{PPV}]=c_{p}\left[\varepsilon_{t}\right]=c_{p} \frac{\left[\sigma_{t}\right]}{E}
$$

where [PPV] is the allowable peak velocity of particle vibration, $\left[\varepsilon_{t}\right]$ is the allowable tensile strain, and $\left[\sigma_{t}\right]$ is the allowable tensile strength of rock.

It is deduced from Eq. (21) that there is a positive relationship between the peak particle velocity and the dynamic tensile strain or the dynamic tensile stress of the rock mass; therefore, according to the dynamic tensile strength $\left[\sigma_{t}\right]$ or dynamic ultimate tensile strain $\left[\varepsilon_{t}\right]$ of rock mass, the allowable threshold value of peak particle velocity [PPV] can be determined.

Due to the complexity of structural dynamic response characteristics, the safety criteria for blasting vibration of building, rock slope, surrounding rock mass of cavern and fresh concrete adopt single particle vibration velocity has great limitation, which cannot fully reflect the integrated influence of blasting frequency and duration of vibration on dynamic characteristics of corresponding structures and rock mass. Thus, the United States, Switzerland, Germany and China simultaneously taken vibration velocity and frequency into account when regulate the safety standards for blasting vibration, where different critical vibration velocities are used at different frequencies. However, there is no systematic research on the effect of duration on the safety criterion of blasting vibration at domestic and foreign.

As shown in Fig. 3, Office of Surface Mining Reclamation and Enforcement (OSMRE) and the United States Bureau of Mines (USBM) in American put forward the relevant safety criterion of blasting vibration [51].

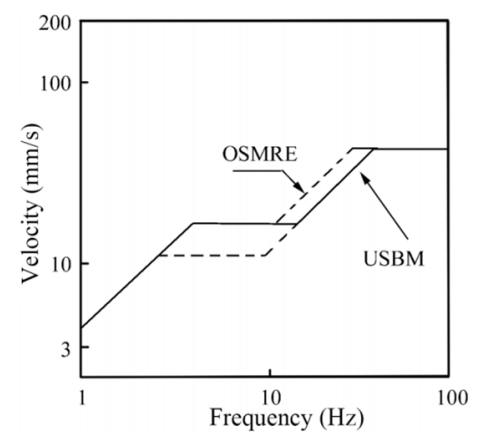

Fig. 3. Safety criteria of USBM and OSMRE

In terms of ground building, central control room equipment at hydropower station and power plant in service, hydraulic tunnel, traffic tunnel, mine tunnel, high rock slope and the new pouring mass concrete, Chinese admissibility standards, i.e. "Safety regulations for blasting" (GB6722-2014) point out safety criteria in consideration of peak particle velocity and dominant frequency. Blasting vibration safety criteria established in China are listed in Table 1. 
Table 1. Blasting vibration criteria at China "Safety regulations for blasting" (GB6722-2014)

\begin{tabular}{|c|c|c|c|c|}
\hline \multirow{2}{*}{$\begin{array}{l}\text { Sequence } \\
\text { number }\end{array}$} & \multirow{2}{*}{ Protective structure } & \multicolumn{3}{|c|}{ Permitted particle vibration velocity $(\mathrm{cm} / \mathrm{s})$} \\
\hline & & $f \leq 10 \mathrm{~Hz}$ & $10 \mathrm{~Hz}<f \leq 50 \mathrm{~Hz}$ & $f>50 \mathrm{~Hz}$ \\
\hline 1 & $\begin{array}{l}\text { Cave dwelling, adobe building and } \\
\text { freestone building }\end{array}$ & $0.15-0.45$ & $0.45-0.9$ & $0.9-1.5$ \\
\hline 2 & Common civil building & $1.5-2.0$ & $2.0-2.5$ & $2.5-3.0$ \\
\hline 3 & $\begin{array}{l}\text { Industrial building } \\
\text { and commercial building }\end{array}$ & $2.5-3.5$ & $3.5-4.5$ & $4.2-5.0$ \\
\hline 4 & $\begin{array}{l}\text { General ancient architecture } \\
\text { and historic site }\end{array}$ & $0.1-0.2$ & $0.2-0.3$ & $0.3-0.5$ \\
\hline 5 & $\begin{array}{c}\text { Central control room equipment } \\
\text { at hydropower station } \\
\text { and power plant in service }\end{array}$ & $0.5-0.6$ & $0.6-0.7$ & $0.7-0.9$ \\
\hline 6 & Hydraulic tunnel & $7-8$ & $8-10$ & $10-15$ \\
\hline 7 & Traffic tunnel & $10-12$ & $12-15$ & $15-20$ \\
\hline 8 & Mine tunnel & $15-18$ & $18-25$ & $20-30$ \\
\hline 9 & Permanently high rock slope & $5-9$ & $8-12$ & $10-15$ \\
\hline 10 & $\begin{array}{c}\text { The new pouring mass } \\
\text { concrete }(\mathrm{C} 20) \text { : } \\
\text { Curing time: initial solidification- } 3 \mathrm{~d} \\
\text { Curing time: } 3 \mathrm{~d}-7 \mathrm{~d} \\
\text { Curing time: } 7 \mathrm{~d}-28 \mathrm{~d}\end{array}$ & $\begin{array}{l}1.5-2.0 \\
3.0-4.0 \\
7.0-8.0\end{array}$ & $\begin{array}{l}2.0-2.5 \\
4.0-5.0 \\
8.0-10.0\end{array}$ & $\begin{array}{c}2.5-3.0 \\
5.0-7.0 \\
10.0-12.0\end{array}$ \\
\hline
\end{tabular}

For new pouring mass concrete $(\mathrm{C} 20)$, the allowable limit of particle vibration velocity is different on the basis of dominant frequency and curing time, when the dominant frequency is $f \leq 10 \mathrm{~Hz}, 10 \mathrm{~Hz}<f \leq 50 \mathrm{~Hz}$ and $f>50 \mathrm{~Hz}$, respectively, for curing time between initial solidification and $3 \mathrm{~d}$, the allowable limit of particle vibration velocity is $1.5-2.0 \mathrm{~cm} / \mathrm{s}, 2.0-2.5 \mathrm{~cm} / \mathrm{s}$ and $2.5-3.0 \mathrm{~cm} / \mathrm{s}$, respectively; for curing time between $3 \mathrm{~d}$ and $7 \mathrm{~d}$, the allowable limit of particle vibration velocity is $3.0-4.0 \mathrm{~cm} / \mathrm{s}, 4.0-5.0 \mathrm{~cm} / \mathrm{s}$ and $5.0-7.0 \mathrm{~cm} / \mathrm{s}$, respectively; for curing time between $7 \mathrm{~d}$ and $28 \mathrm{~d}$, the allowable limit of particle vibration velocity is $7.0-8.0 \mathrm{~cm} / \mathrm{s}$, $8.0-10.0 \mathrm{~cm} / \mathrm{s}$ and $10.0-12 \mathrm{~cm} / \mathrm{s}$, respectively.

Table 2. PPV criterion for the blast induced damage [54]

\begin{tabular}{|c|c|}
\hline Peak particle velocity $(\mathrm{cm} / \mathrm{s})$ & Effects of damage \\
\hline$<25.0$ & No fracturing of intact rock \\
\hline $25.0-63.5$ & Millar tensile slabbing will occur \\
\hline $63.5-254.0$ & Strong tensile and some radial cracking \\
\hline 254.0 & Complete break-up of rock mass \\
\hline
\end{tabular}

Table 3. PPV criterion for the blast induced damage [55]

\begin{tabular}{|c|c|c|c|c|c|}
\hline \multirow[b]{2}{*}{ Rock type } & \multirow[b]{2}{*}{$\begin{array}{l}\text { Uniaxial compressive } \\
\text { strength (MPa) }\end{array}$} & \multirow[b]{2}{*}{ RQD (\%) } & \multicolumn{3}{|c|}{ Peak particle velocity $(\mathrm{cm} / \mathrm{s})$} \\
\hline & & & $\begin{array}{l}\text { Minor } \\
\text { damage }\end{array}$ & $\begin{array}{l}\text { Medium } \\
\text { damage }\end{array}$ & $\begin{array}{l}\text { Heavy } \\
\text { damage }\end{array}$ \\
\hline Soft schist & $14-30$ & 20 & $13.0-15.5$ & $15.5-35.5$ & $>35.5$ \\
\hline Hard schist & 49 & 50 & $23.0-35.0$ & $35.0-60.0$ & $>60.0$ \\
\hline Shultze granite & $30-55$ & 40 & $31.0-47.0$ & $47.0-170.0$ & $>170.0$ \\
\hline Porphyry granite & $30-85$ & 40 & $44.0-77.5$ & $77.5-124.0$ & $>124.0$ \\
\hline
\end{tabular}

A number of safety criteria for peak vibration velocity of rock mass cracking have been put forward at home and abroad by new crack investigation and acoustic test before and after bedrock blasting. For example, Langefors and Kihlstrom [42] take the peak particle velocity of $60 \mathrm{~cm} / \mathrm{s}$ as the critical value of new rock cracks; Zhang [52] measured the micro-cracking zone boundaries of rock mass in blasting using the computer tomography (CT) and the allowed critical vibration velocities of rock particles are calculated which are 13.8-16.6 cm/s. Huang et al. [53] found that 
the remained bedrock was very slightly damaged when the PPV of rock mass is under $3.5 \mathrm{~cm} / \mathrm{s}$. Bauer A. [54] and Mojitabai N. [55] suggested the safety criterion for the peak vibration velocity for the blasting damage of the rock mass is shown in Table 2 and Table 3 , respectively; it is shown that there is no fracturing damage of intact rock for blasting excavation when peak particle velocity is under $25.0 \mathrm{~cm} / \mathrm{s}$, minor damage will exist when the peak vibration velocity is greater than $13.0-15.5 \mathrm{~cm} / \mathrm{s}, 23.0-35.0 \mathrm{~cm} / \mathrm{s}, 31.0-47.0 \mathrm{~cm} / \mathrm{s}$ and $44.0-77.5 \mathrm{~cm} / \mathrm{s}$ for soft schist, hard schist, shultze granite and granite porphyry, respectively.

\section{Case study}

\subsection{Introduction to Xianning Nuclear power station}

The Xianning Nuclear Power Plant with a total installed capacity of $6000 \mathrm{MW}(4 \times 1000 \mathrm{MW})$ Advanced passive pressurized water reactor (AP1000) lies on Xianning city, the south of Hubei Province, China. Its geographical location is at longitude $114^{\circ} 40^{\prime} 52^{\prime \prime} \mathrm{E}$ and latitude $29^{\circ} 40^{\prime} 38^{\prime \prime} \mathrm{N}$, The project construction scale will be divided into two phases and two AP1000 nuclear power units are planned in the first phase.

In construction site of the blasting for foundation excavation of the road corridor, the blasting seismic monitoring has been conducted in order to reduce the damage extent to the new pouring mass concrete and surrounding rock mass; the overview of the Xianning Nuclear Power Station, the layout of blasting vibration monitoring points and the blasting vibration monitoring system for foundation excavation blasting is shown in Fig. 4, Fig. 5, and Fig. 6, respectively.

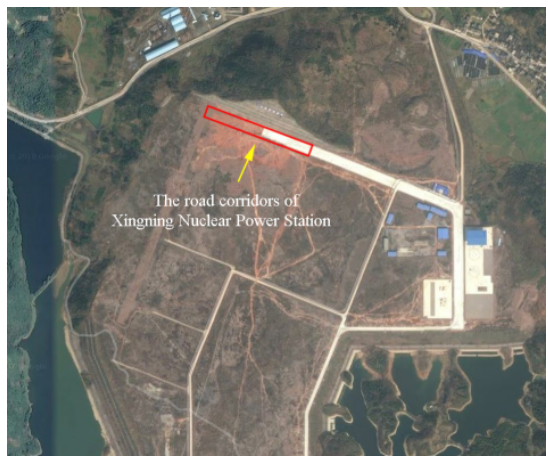

Fig. 4. The overview of the Xianning Nuclear Power Station

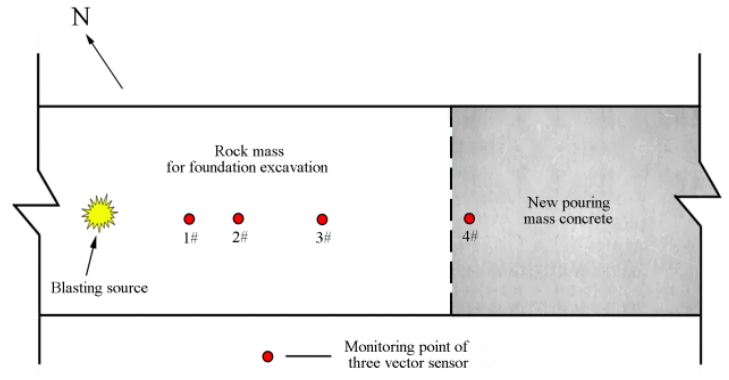

Fig. 5. The layout of blasting vibration monitoring points

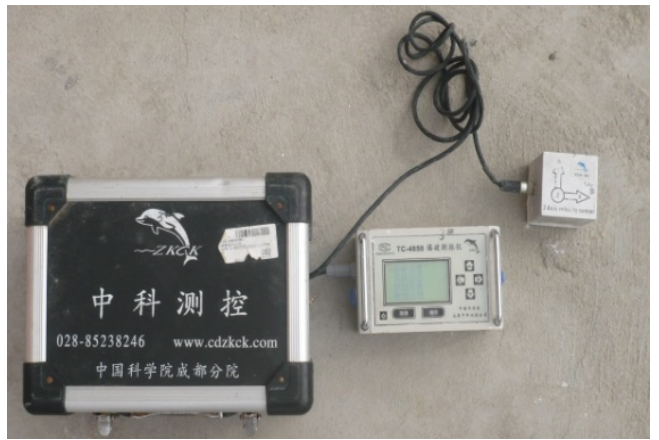

Fig. 6. Blasting vibration monitoring system

\subsection{Peak particle velocity attenuation law}

During the experiments, 252 blasting vibration data along the horizontal radial, horizontal 
tangential and vertical direction were recorded from 84 blasting monitoring points of 19 shots. Summary of experimental blast design parameters at road corridor in Xianning nuclear power station is given in Table 4. Parts of vibration measurement results of peak particle velocity under explosion are shown in Table 5.

Table 4. Summary of blast design parameters at road corridor in Xianning nuclear power station

\begin{tabular}{|c|c|c|c|c|c|c|c|c|c|}
\hline $\begin{array}{c}\text { No. } \\
\text { of } \\
\text { shots }\end{array}$ & $\begin{array}{c}\text { Diameter } \\
\text { of hole } \\
(\mathrm{mm})\end{array}$ & $\begin{array}{c}\text { Burden } \\
(\mathrm{m})\end{array}$ & $\begin{array}{c}\text { Spacing } \\
(\mathrm{m})\end{array}$ & $\begin{array}{c}\text { Depth of } \\
\text { blast } \\
\text { hole } \\
(\mathrm{m})\end{array}$ & $\begin{array}{c}\text { Length of } \\
\text { stemming } \\
(\mathrm{m})\end{array}$ & $\begin{array}{c}\text { Total } \\
\text { charge } \\
(\mathrm{kg})\end{array}$ & $\begin{array}{c}\text { Maximum } \\
\text { charge } \\
\text { per delay } \\
(\mathrm{kg})\end{array}$ & $\begin{array}{c}\text { Initiation } \\
\text { systems }\end{array}$ & Explosives \\
\hline 19 & 90 or 115 & $2.2-3.0$ & $2.2-2.5$ & $2.7-8.8$ & $2.0-3.5$ & $300-1107$ & $40-184$ & $\begin{array}{c}\text { Non-electric } \\
\text { shock tube } \\
\text { delay } \\
\text { detonator and } \\
\text { milli-second } \\
\text { connector }\end{array}$ & $\begin{array}{c}\text { Emulsion } \\
\text { explosive }\end{array}$ \\
\hline
\end{tabular}

Table 5. Parts of vibration measurement results of peak particle velocity under explosion

\begin{tabular}{|c|c|c|c|c|c|c|c|c|c|c|}
\hline \multirow{2}{*}{$\begin{array}{c}\text { Sequence } \\
\text { No. }\end{array}$} & \multirow{2}{*}{$\begin{array}{c}\text { Measuring } \\
\text { point } \\
\text { location }\end{array}$} & \multirow{2}{*}{$\begin{array}{l}\text { Maximum } \\
\text { explosive } \\
\text { weight per } \\
\text { delay }(\mathrm{kg})\end{array}$} & \multirow{2}{*}{$\begin{array}{c}\text { Total } \\
\text { explosive } \\
\text { weight }(\mathrm{kg})\end{array}$} & \multirow{2}{*}{$\begin{array}{c}\text { Distance } \\
(\mathrm{m})\end{array}$} & \multicolumn{2}{|c|}{$\begin{array}{l}\text { Horizontal } \\
\text { radial } \\
\text { direction }\end{array}$} & \multicolumn{2}{|c|}{$\begin{array}{c}\text { Horizontal } \\
\text { tangential } \\
\text { direction }\end{array}$} & \multicolumn{2}{|c|}{$\begin{array}{c}\text { Vertical } \\
\text { direction }\end{array}$} \\
\hline & & & & & $\begin{array}{l}\mathrm{PPV}_{\mathrm{x}} \\
(\mathrm{cm} / \mathrm{s})\end{array}$ & $\begin{array}{c}f \\
(\mathrm{~Hz})\end{array}$ & $\begin{array}{l}\mathrm{PPV}_{\mathrm{y}} \\
(\mathrm{cm} / \mathrm{s})\end{array}$ & $\begin{array}{c}f \\
(\mathrm{~Hz})\end{array}$ & $\begin{array}{l}\mathrm{PPV}_{\mathrm{z}} \\
(\mathrm{cm} / \mathrm{s})\end{array}$ & $\begin{array}{c}f \\
(\mathrm{~Hz})\end{array}$ \\
\hline 1 & rock mass & 93 & 408 & 27 & 3.42 & 15.62 & 3.25 & 41.66 & 3.12 & 41.66 \\
\hline 2 & rock mass & 93 & 408 & 44 & 1.51 & 55.55 & 1.84 & 62.50 & 1.96 & 29.41 \\
\hline 3 & concrete & 93 & 408 & 138 & 0.28 & 27.77 & 0.23 & 25.00 & 0.23 & 27.77 \\
\hline 4 & rock mass & 104 & 634 & 27 & 4.03 & 83.33 & 3.66 & 41.66 & 3.89 & 18.52 \\
\hline 5 & rock mass & 104 & 634 & 30 & 3.74 & 20.00 & 3.13 & 29.41 & 3.38 & 38.46 \\
\hline 6 & rock mass & 104 & 634 & 37 & 2.54 & 62.50 & 2.13 & 38.46 & 2.12 & 62.50 \\
\hline 7 & concrete & 104 & 634 & 90 & 0.36 & 41.67 & 0.31 & 62.50 & 0.38 & 41.67 \\
\hline 8 & rock mass & 80 & 400 & 30 & 3.57 & 47.50 & 3.11 & 48.46 & 3.35 & 38.50 \\
\hline 9 & rock mass & 80 & 400 & 37 & 2.34 & 25.50 & 2.41 & 30.41 & 2.17 & 20.46 \\
\hline 10 & rock mass & 80 & 400 & 49 & 1.73 & 51.67 & 1.83 & 50.50 & 1.32 & 21.67 \\
\hline 11 & concrete & 80 & 400 & 110 & 0.62 & 20.12 & 1.12 & 34.12 & 0.73 & 18.25 \\
\hline 12 & rock 1 & 96 & 6 & 27 & 3.06 & 45.45 & 2.91 & 31.25 & 2.91 & 50.00 \\
\hline 13 & rock & 96 & & 37 & 2.66 & 41.66 & 2.82 & 38.46 & 2.75 & 50.78 \\
\hline 14 & rock mass & 96 & 666 & 74 & 0.94 & 27.77 & 0.82 & 31.25 & 0.56 & 45.45 \\
\hline 15 & concrete & 96 & 666 & 183 & 0.07 & 62.50 & 0.18 & 41.67 & 0.12 & 25.00 \\
\hline 16 & rock mass & 80 & 400 & 24 & 3.50 & 46.45 & 3.11 & 56.25 & 2.40 & 52.00 \\
\hline 17 & rock mass & 80 & 400 & 37 & 2.30 & 35.71 & 2.19 & 22.73 & 2.12 & 55.55 \\
\hline 18 & rock mass & 80 & 400 & 44 & 2.19 & 62.50 & 2.05 & 45.45 & 1.55 & 45.45 \\
\hline 19 & rock mass & 80 & 400 & 57 & 1.02 & 41.66 & 0.95 & 41.67 & 1.28 & 38.46 \\
\hline 20 & concrete & 80 & 400 & 96 & 0.54 & 25.00 & 0.48 & 25.88 & 0.69 & 55.56 \\
\hline
\end{tabular}

For foundation excavation blasting, total 117 blasting vibration data from 39 blasting monitoring points of first 10 shots from bench blasting are selected to fit in the form of power function based on Eq. (4); The regression analysis results of peak particle velocity, PPV, and the scaled distance, SD, along the horizontal radial, horizontal tangential and vertical direction are shown in Fig. 7.

The Duvall Formula on regressive analysis along the horizontal radial, horizontal tangential and vertical direction is expressed as Eq. (22), Eq. (23) and Eq. (24), respectively. The determination coefficients $\left(R^{2}\right)$ for Eq. (22), Eq. (23) and Eq. (24) is 0.92, 0.87 and 0.87, respectively, it indicates that the power law of attenuation Eq. (4) has a good fitting consistency:

$\mathrm{PPV}_{\mathrm{x}}=16.0(S D)^{-1.38}$, 
$\operatorname{PPV}_{\mathrm{y}}=11.7(S D)^{-1.17}$
$\operatorname{PPV}_{\mathrm{z}}=10.0(S D)^{-1.11}$

The blast-induced peak particle velocity attenuation law is obtained in the form of Eq. (22), Eq. (23), and Eq. (24), based on the above equation, we can effectively present the blasting design about the maximum explosive weight per delay, $Q$, according to the allowable peak particle velocity, $\mathrm{PPV}_{\text {limit }}$, at different distance from the center of explosion, $R$, in terms of requisition of "Safety regulations for blasting" (GB6722-2014) and expert opinion in China:

$\mathrm{PPV}_{\text {limit }} \geq \max \left\{\mathrm{PPV}_{x}, \mathrm{PPV}_{y}, \mathrm{PPV}_{z}\right\}$.

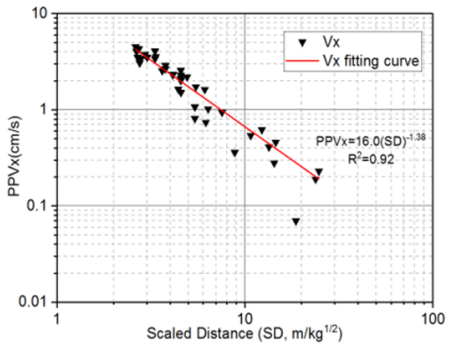

a) Horizontal radial direction

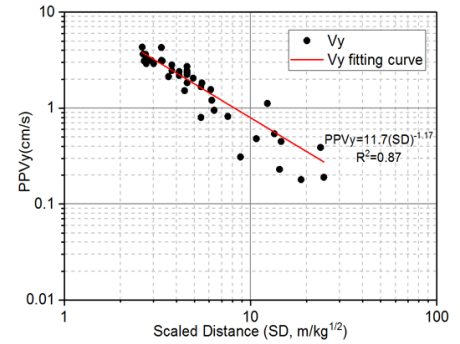

b) Horizontal tangential direction

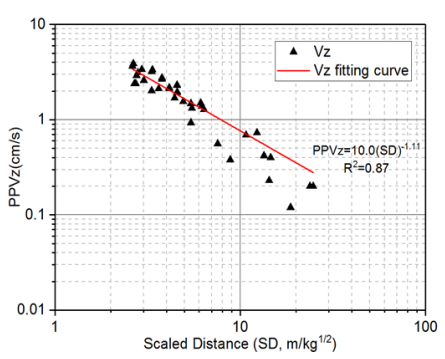

c) Vertical direction

Fig. 7. The regression analysis of blast vibration velocity

In term of Duvall empirical formula in Eq. (4), parameter $K$ is directly proportional to particle vibration velocity and parameter $a$ represent declining speed of particle vibration velocity where the bigger of $a$, the faster of velocity attenuation along propagation distance. It is observed in Eqs. (22-24) that the range of variation for $K$ is from 10.0 to 16.0 and $a$ is from 1.11 to 1.38 where it has been observed that $K, a$ of horizontal radial direction is largest, this is, 16.0 and 1.38 , respectively; but $K, a$ of horizontal tangential direction is 11.7 and 1.17 , respectively and $K, a$ of vertical direction is 10.0 and 1.11 , respectively. It is easy seen that the $K$ of horizontal radial direction is more than horizontal tangential and vertical direction while $a$ of horizontal radial direction is also more than horizontal tangential and vertical direction, it mean that horizontal radial direction has faster speed of velocity attenuation, As consistent with the results shown in Table 5, in spite of PPV of horizontal radial direction generally is larger than horizontal tangential and vertical direction in the near field of blasting source, however, the PPV of horizontal radial direction will be lower than horizontal tangential and vertical direction in the far field of blasting source. So it is noteworthy that we should take three different direction components of particle vibration velocity rather than single direction into account as safety criteria for blasting vibration.

\subsection{Time-frequency characteristics for blasting vibration signal}

As shown in Fig. 8, there is a typical multiple section raw signal of millisecond blasting seismic wave with four sections of electric detonator monitored at $37 \mathrm{~m}$ away from the explosion source. The sampling points are 1000 and sampling interval time is $0.001 \mathrm{~s}$. The original vibration signal (Fig. 8) will be decomposed and reconstructed by wavelet transform, the selection of wavelet basis function is the most direct problem in the application of wavelet analysis, since there is not absolutely same conclusion when different wavelet basis function is used to analyze the same signal, the selection of wavelet basis function has an important influence on the correctness of signal analysis; the commonly used wavelet basis function of non-stationary vibration signal analysis mainly come from $\mathrm{db} 3, \mathrm{db} 5$, sym 5 and coif3; through the comparative analysis of signal reconstruction and relative error of blasting vibration signal, it is found that $\mathrm{db} 3, \mathrm{db} 5$, sym 5 and coif3 wavelet basis function all have good reconstruction ability and extremely low relative error 
range within the order of $10^{-11}[29,56,57]$, where $\mathrm{db} 5$ is chosen as the wavelet basis function of wavelet transform for blasting vibration signal.

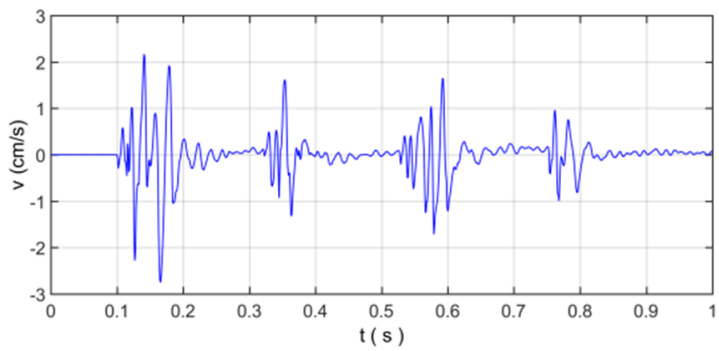

Fig. 8. The velocity curve of original vibration signal

According to the characteristics of the instrument and sampling theorem, the sampling frequency of the signal is set to $1000 \mathrm{~Hz}$, and the Nyquist frequency of the signal is $500 \mathrm{~Hz}$. Therefore, according to the principle of wavelet analysis (Fig. 1), the original vibration signal is decomposed into 7 levels and total 8 frequency band signal, i.e. a7 and d1-d7 wavelet components is obtained, in which a7 is low frequency component, d1-d7 is high frequency component. The decomposed vibration signal is shown in Fig. 9, the reconstructed vibration signal and relative error are shown in Fig. 10.
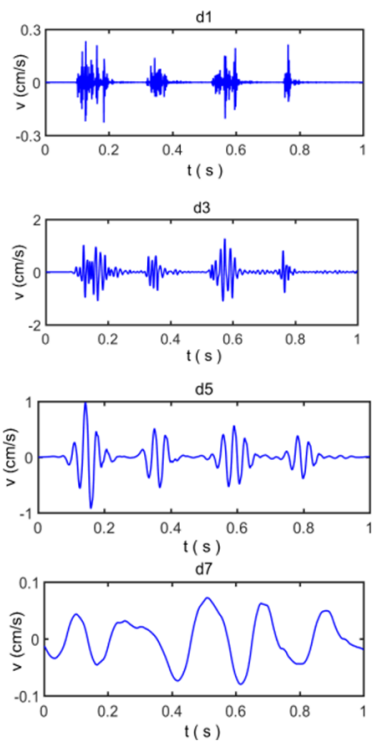
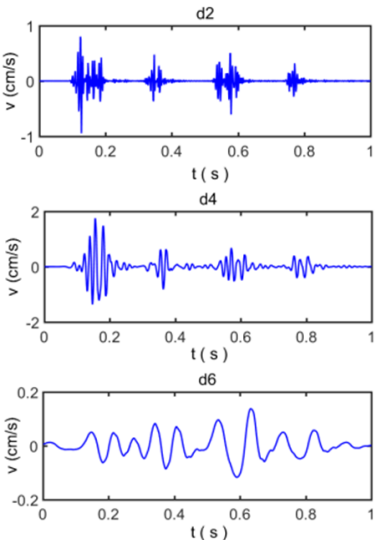

a7

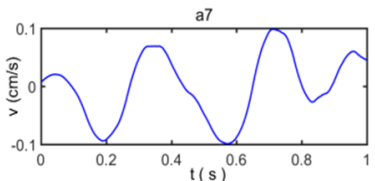

Fig. 9. The decomposed vibration signals by wavelet transform

Because wavelet transform always decompose the sub band of the low frequency signal and no longer decompose the sub band of high frequency signal in the process of wavelet analysis, the band range of a7, d7, d6, d5, d4, d3, d2, and d1 is $0-3.9063 \mathrm{~Hz}, 3.9063-7.8125 \mathrm{~Hz}, 7.8125-$ $15.625 \mathrm{~Hz}, 15.625-31.25 \mathrm{~Hz}, 31.25-62.5 \mathrm{~Hz}, 62.5-125 \mathrm{~Hz}, 125-250 \mathrm{~Hz}$, and $250-500 \mathrm{~Hz}$, respectively. The wavelet component $\mathrm{d} 1$ has a very small amplitude reflect the energy of original vibration signal in $250-500 \mathrm{~Hz}$ is very small, the wavelet component $\mathrm{d} 2, \mathrm{~d} 3, \mathrm{~d} 4, \mathrm{~d} 5 \mathrm{have}$ observably larger amplitude than other wavelet components which show the energy of original vibration signal in $15.625-250 \mathrm{~Hz}$ constitutes a majority of energy of original vibration signal and become main component to influence of building vibration; the wavelet component $\mathrm{d} 6$, d7, a7 have less amplitude of original vibration signal reflects the energy of original vibration signal in 
$0-15.625 \mathrm{~Hz}$ is also small.

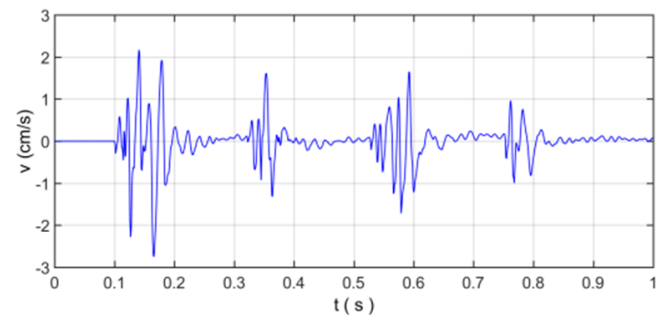

a) Reconstruction signal based on wavelet transform

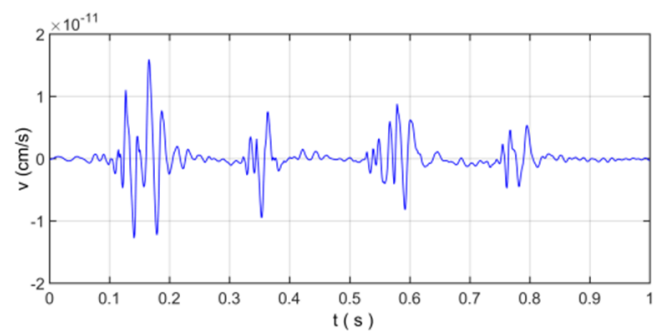

b) Relative error based on wavelet transform

Fig. 10. The reconstructed vibration signal and relative error based on wavelet transform

As is shown in Fig. 10, the reconstructed vibration signal based on wavelet transform is very consistently similar to original vibration signal with relative error is $10^{-11}$, which shows that wavelet transform can accurately reflect the characteristics of the non-stationary signal and have an excellent suitability for analysis on blasting vibration signal.

Fig. 11 shows power spectrum density of original vibration signal (Fig. 8) and Fig. 12 shows power spectrum density of wavelet component from d1 to d7 and a7 (Fig. 9).

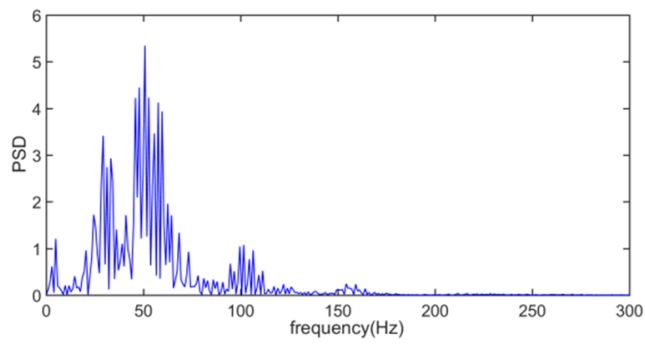

Fig. 11. The power spectral density of original vibration signal

Fig. 11 indicates the blast energy of original vibration signal is mainly within the frequency below $250 \mathrm{~Hz}$ region and has three sub-band which varies from $10 \mathrm{~Hz}$ to $30 \mathrm{~Hz}$, from $40 \mathrm{~Hz}$ to $70 \mathrm{~Hz}$ and from $75 \mathrm{~Hz}$ to $125 \mathrm{~Hz}$, respectively, in which the main energy concentrates in the range of $40 \mathrm{~Hz}$ to $70 \mathrm{~Hz}$, and the energy in the range of $10 \mathrm{~Hz}$ to $30 \mathrm{~Hz}$ and $75 \mathrm{~Hz}$ to $125 \mathrm{~Hz}$ is relatively weak.

The natural frequencies of common buildings are between $1 \mathrm{~Hz}$ and $10 \mathrm{~Hz}$, from the perspective of security, low energy distribution in the low frequency region is beneficial to structural safety and stability of surrounding rock for reducing the probability of resonance $[40,58]$.

It can be seen in Fig. 12 that the frequency range about power spectrum density of wavelet component d1 is widely distributed in the range from $220 \mathrm{~Hz}$ to $500 \mathrm{~Hz}$ and the amplitude of power spectrum density of wavelet component $\mathrm{d} 1$ is extremely low. The frequency range of wavelet component d2 mainly varies from $80 \mathrm{~Hz}$ to $250 \mathrm{~Hz}$ and the corresponding amplitude of power spectrum density is relatively weak. The wavelet component $\mathrm{d} 3, \mathrm{~d} 4, \mathrm{~d} 5$ occupies the spectral range from $50 \mathrm{~Hz}$ to $120 \mathrm{~Hz}$, from $30 \mathrm{~Hz}$ to $80 \mathrm{~Hz}$, and from $15 \mathrm{~Hz}$ to $35 \mathrm{~Hz}$, respectively and constitute the main energy of original vibration signal, in addition, the dominant frequency of d6, d7, a7 is below $15 \mathrm{~Hz}$ and energy density spectrum is also low.

The three-dimensional energy density spectrum of original vibration signal on wavelet transform is showed in Fig. 13. 


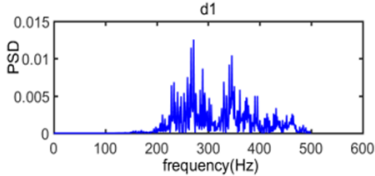

d3

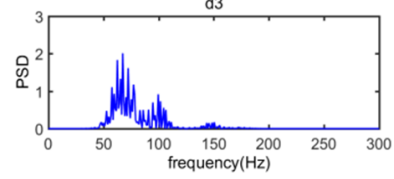

d5

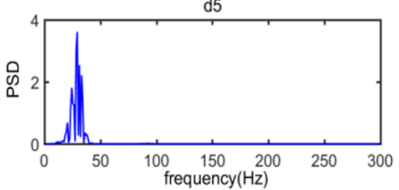

d7

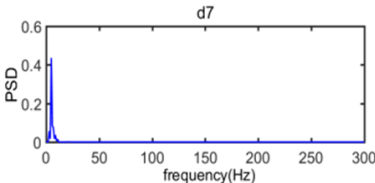

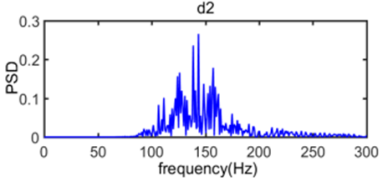

d4

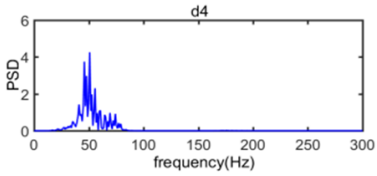

d6

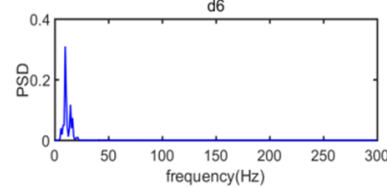

a7

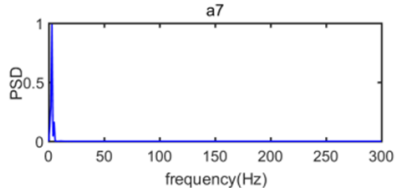

Fig. 12. The power spectrum density of wavelet component from $d 1$ to $d 7$ and a7

Fig. 13 presented the distribution characteristics about energy of blasting vibration signal as the variation of frequency and time; It can be more intuitive to show the distribution of energy on blasting vibration signal with time and frequency, where the color is redder, the energy is greater, we can see that the energy mainly concentrates on the range of $10 \mathrm{~Hz}-125 \mathrm{~Hz}$ and $100-800$ time sampling point, where the main frequency is located at $50 \mathrm{~Hz}$ in frequency domain and there are energy peaks near 170, 360, 590 and 780, respectively in the time sampling point. Dividing time sampling point $100-800$ by sampling frequency $1000 \mathrm{~Hz}$ is $0.10 \mathrm{~s}-0.80 \mathrm{~s}$, we can obtain the energy mainly concentrates on the range of $10 \mathrm{~Hz}-125 \mathrm{~Hz}$ and $0.10 \mathrm{~s}-0.80 \mathrm{~s}$. The time frequency distribution characteristics about energy based on Wavelet transform is in accordance with the velocity curve of original vibration signal in Fig. 8 where the time region for velocity vibration amplitude mainly vary from $0.10 \mathrm{~s}$ to $0.80 \mathrm{~s}$ and there are four velocity amplitude peaks in $0.17 \mathrm{~s}$, $0.36 \mathrm{~s}, 0.59 \mathrm{~s}$ and $0.78 \mathrm{~s}$, respectively and the power spectral density of original vibration signal in Fig. 11 where the frequency region for power spectral density mainly concentrate on $10 \mathrm{~Hz}-125 \mathrm{~Hz}$ where peak of power spectral density is located at $50 \mathrm{~Hz}$.

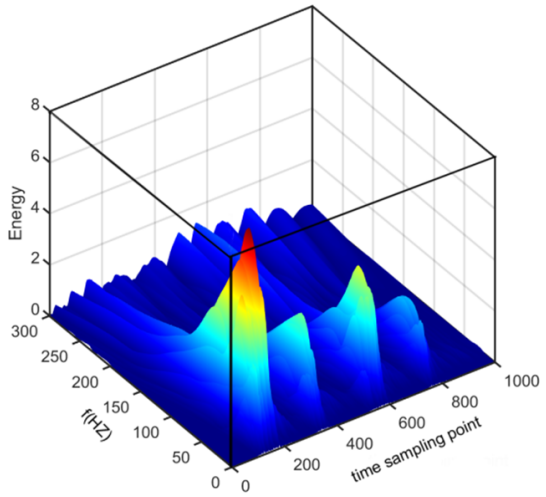

Fig. 13. Time frequency distribution of energy based on Wavelet transform

In the case of wavelet packet analysis for blasting vibration signal, the number of layers of wavelet packet decomposition is needed. The sampling frequency of the blasting vibration signal 
is determined as $1000 \mathrm{~Hz}$, the Nyquist frequency is $500 \mathrm{~Hz}$ on the basis of Shannon sampling theorem [49], According to the principle of wavelet packet analysis, the blasting vibration signal is decomposed to seventh layers, with a total of $2^{7}$ i.e., 128 wavelet packets and each frequency bandwidth is $3.91 \mathrm{~Hz}$, in which corresponding to the lowest frequency band is $0-3.91 \mathrm{~Hz}$. The frequency bands for the reconstructed signals of each layer after wavelet packet decomposition of the blasting vibration signal are shown in Table 6.

Table 6. The range for frequency band of reconstructed signal by wavelet packet decomposition

\begin{tabular}{|c|c|c|c|c|c|c|}
\hline Number of layers & $s_{i, 0}(\mathrm{~Hz})$ & $s_{i, 1}(\mathrm{~Hz})$ & $s_{i, 2}(\mathrm{~Hz})$ & & $s_{i, j-1}(\mathrm{~Hz})$ & $s_{i, j}(\mathrm{~Hz})$ \\
\hline 1 & $0-250$ & & & & & $250-500$ \\
\hline 2 & $0-125$ & $125-250$ & $250-375$ & & & $375-500$ \\
\hline 3 & $0-62.5$ & $62.5-125$ & $125-187.5$ & $\ldots$ & $375-437.5$ & $437.5-500$ \\
\hline 4 & $0-31.25$ & $31.25-62.5$ & $62.5-93.75$ & $\ldots$ & $437.5-468.75$ & $468.75-500$ \\
\hline 5 & $0-15.63$ & $15.63-31.25$ & $31.25-46.88$ & $\ldots$ & $468.75-484.38$ & $484.38-500$ \\
\hline 6 & $0-7.82$ & $7.82-15.63$ & $15.63-23.44$ & $\ldots$ & $484.38-492.19$ & $492.19-500$ \\
\hline 7 & $0-3.91$ & $3.91-7.82$ & $7.82-11.72$ & $\ldots$ & $492.19-496.09$ & $496.09-500$ \\
\hline
\end{tabular}

The energy of blasting vibration signal will change in different frequency bands. The vibration signal can be subdivided into different frequency bands by wavelet packet and the corresponding energy in each frequency band can be obtained, which can observably reflects the characteristics of blasting vibration. The calculation in this paper is based on Eqs. (17-20) in MATLAB. The energy of blasting vibration signals is mainly concentrated in $0-300 \mathrm{~Hz}$, so the energy percentage in different frequency bands for the total energy of the signal is shown in Table 7 and Fig. 14.

Table 7. The frequency band energy percentage decomposed by wavelet packet decomposition

\begin{tabular}{|c|c|c|c|c|c|c|c|}
\hline $\begin{array}{c}\text { Frequency } \\
\text { band (Hz) }\end{array}$ & $\begin{array}{c}\text { Energy } \\
\text { percentage } \\
(\%)\end{array}$ & $\begin{array}{c}\text { Frequency } \\
\text { band (Hz) }\end{array}$ & $\begin{array}{c}\text { Energy } \\
\text { percentage } \\
(\%)\end{array}$ & $\begin{array}{c}\text { Frequency } \\
\text { band (Hz) }\end{array}$ & $\begin{array}{c}\text { Energy } \\
\text { percentage } \\
(\%)\end{array}$ & $\begin{array}{c}\text { Frequency } \\
\text { band (Hz) }\end{array}$ & $\begin{array}{c}\text { Energy } \\
\text { percentage } \\
(\%)\end{array}$ \\
\hline $0-3.91$ & 1.58 & $74.22-78.13$ & 0.50 & $148.44-152.34$ & 0.09 & $222.66-226.56$ & 0.04 \\
\hline $3.91-7.82$ & 0.73 & $78.13-82.03$ & 1.83 & $152.34-156.25$ & 0.05 & $226.56-230.47$ & 0.01 \\
\hline $7.82-11.72$ & 0.26 & $82.03-85.94$ & 2.12 & $156.25-160.02$ & 0.06 & $230.47-234.38$ & 0.05 \\
\hline $11.72-15.63$ & 0.69 & $85.94-89.84$ & 0.40 & $160.02-164.06$ & 0.09 & $234.38-238.28$ & 0.37 \\
\hline $15.63-19.93$ & 13.70 & $89.84-93.75$ & 0.96 & $164.06-167.97$ & 0.04 & $238.28-242.19$ & 0.06 \\
\hline $19.93-23.44$ & 5.77 & $93.75-97.66$ & 5.26 & $167.97-171.88$ & 0.10 & $242.19-246.09$ & 0.14 \\
\hline $23.44-27.34$ & 0.37 & $97.66-101.56$ & 7.45 & $171.88-175.78$ & 0.08 & $246.09-250.00$ & 0.33 \\
\hline $27.34-31.25$ & 1.62 & $101.56-105.47$ & 3.80 & $175.78-179.69$ & 0.03 & $250.00-253.91$ & 0.00 \\
\hline $31.25-35.16$ & 4.64 & $105.47-109.38$ & 2.63 & $179.69-183.59$ & 0.04 & $253.91-257.81$ & 0.00 \\
\hline $35.16-39.06$ & 2.26 & $109.38-113.28$ & 0.57 & $183.59-187.50$ & 0.07 & $257.81-261.72$ & 0.00 \\
\hline $39.06-42.97$ & 7.87 & $113.28-117.19$ & 0.88 & $187.50-191.41$ & 0.69 & $261.72-265.63$ & 0.00 \\
\hline $42.97-46.88$ & 14.67 & $117.19-121.09$ & 1.21 & $191.41-195.31$ & 0.29 & $265.63-269.53$ & 0.00 \\
\hline $46.88-50.78$ & 1.01 & $121.09-125.00$ & 0.79 & $195.31-199.22$ & 0.62 & $269.53-273.44$ & 0.00 \\
\hline $50.78-54.69$ & 1.93 & $125.00-128.91$ & 0.03 & $199.22-203.13$ & 0.52 & $273.44-277.34$ & 0.00 \\
\hline $54.69-58.59$ & 4.96 & $128.91-132.81$ & 0.04 & $203.13-207.03$ & 0.42 & $277.34-281.25$ & 0.00 \\
\hline $58.59-62.50$ & 3.19 & $132.82-136.72$ & 0.02 & $207.03-210.94$ & 0.43 & $281.25-285.16$ & 0.00 \\
\hline $62.50-66.41$ & 0.07 & $136.72-140.63$ & 0.02 & $210.94-214.84$ & 0.18 & $285.16-289.06$ & 0.00 \\
\hline $66.41-70.31$ & 0.03 & $140.63-144.53$ & 0.02 & $214.84-218.75$ & 0.17 & $289.06-292.97$ & 0.00 \\
\hline $70.31-74.22$ & 0.49 & $144.53-148.44$ & 0.04 & $218.75-222.66$ & 0.05 & $292.97-500.00$ & 0.52 \\
\hline
\end{tabular}

From Table 7 and Fig. 14, we can see that the energy of the signal between 0 and $250 \mathrm{~Hz}$ accounts for $99.48 \%$ of the total energy of the signal, which indicates that although the energy of the blasting vibration signal is widely distributed in the different frequency domain, but most of the energy is concentrated in the range between 0 and $250 \mathrm{~Hz}$. The ratio of the energy of the signal above $250 \mathrm{~Hz}$ to the total energy is only $0.52 \%$, which indicating that the extremely high frequency components (above $250 \mathrm{~Hz}$ ) of the blasting vibration signal are very few. The energy 
of the signal in $0-125 \mathrm{~Hz}$ accounts for $94.25 \%$ of the total signal and the energy percentage between the $11.72-31.25 \mathrm{~Hz}, 39.06-70.31 \mathrm{~Hz}$ and $74.22-125 \mathrm{~Hz}$ is $22.15 \%, 33.73 \%$ and $28.40 \%$, respectively, this phenomenon reflect that the dominant energy of the millisecond delay blasting vibration signal is mainly distributed in the main frequency band, and the main frequency band can be divided into multiple sub frequency band.

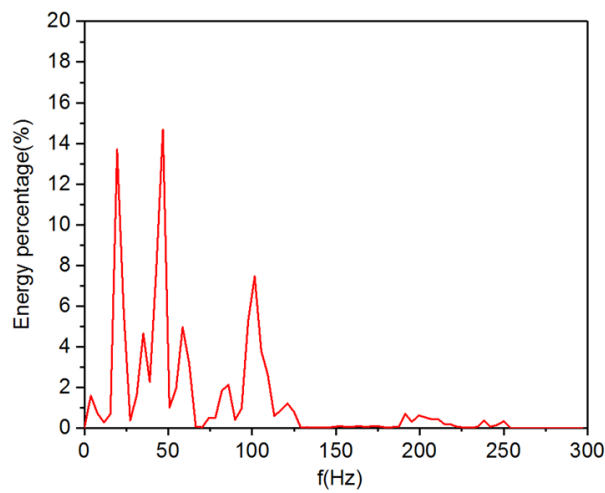

Fig. 14. The frequency band energy percentage of vibration signal

\subsection{Initiative control for blasting vibration effect}

Blasting vibration effect is affected by the blasting design parameters, topography parameters and geology parameters, where the blasting design parameters include the explosive charge, explosive distance, hole-pattern parameters, charging structure, initiation method, and millisecond blasting delay time; topography parameters contain subdued topography, concave topography, convex topography and inclination topography; geology parameters involve rock property, rock structure, fault distribution, and hydrological conditions, etc. In this study, the initiative control for blasting vibration effect is mainly by controlling maximum explosive weight per delay and total explosive weight, meanwhile, adopting decoupling charge and millisecond delay blasting technology; in which the emulsion explosive has a diameter of $32 \mathrm{~mm}$, diameter of hole is $90 \mathrm{~mm}$ or $115 \mathrm{~mm}$, therefore, the radial uncoupling coefficient of about 2.81 or 3.59 ; in addition, four multiple section of non-electric shock tube delay detonator is usually used with millisecond connector.

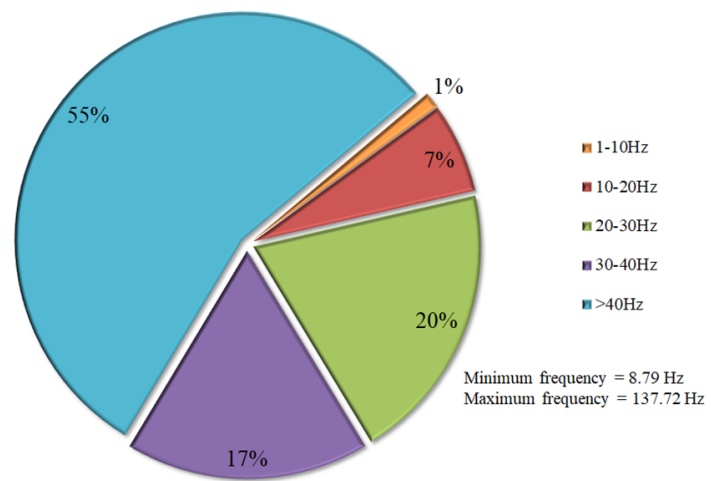

Fig. 15. The dominant frequency distributions of all particle velocity

The dominant frequency distributions of all particle velocity are given in Fig. 15. This graph shows that the percentage distribution of blasting vibration signal is $1 \%, 7 \%, 20 \%, 17 \%$ and $55 \%$ when dominant frequency distribution varies from $1-10 \mathrm{~Hz}, 10-20 \mathrm{~Hz}, 20-30 \mathrm{~Hz}, 30-40 \mathrm{~Hz}$ 
and above $40 \mathrm{~Hz}$, in which the maximum frequency and minimum frequency is $137.72 \mathrm{~Hz}$ and $8.79 \mathrm{~Hz}$, respectively.

In consistent with the standards of the United States Bureau of Mines (USBM), Siskind et al. [59] point out damage potentials for low-frequency blasts $(<40 \mathrm{~Hz})$ are considerably higher than those for high-frequency blasts $(>40 \mathrm{~Hz})$, with the latter often produced by close-in construction and excavation blasts. A major part of the recorded dominant frequencies is greater than $40 \mathrm{~Hz}$, hence, it can be said that the blasting site of foundation excavation can be classified as a moderate -frequency site. Because the natural frequencies of common buildings are between $1 \mathrm{~Hz}$ and $10 \mathrm{~Hz}$, the ratio of vibrations with dominant frequencies of lower than $10 \mathrm{~Hz}$ only is $1 \%$, it is difficult to produce resonance phenomenon, which is beneficial to the safety of structure and rock mass $[40,58]$.

In order to perform controlled blasting, the relationship between the maximum explosive weight per delay and the blast-center distance at different maximum allowable PPV $\mathrm{V}_{\text {limit }}$ can be calculated as Fig. 16. It is able to determine maximum charge weight per delay for any shot in close distances to the road corridor.

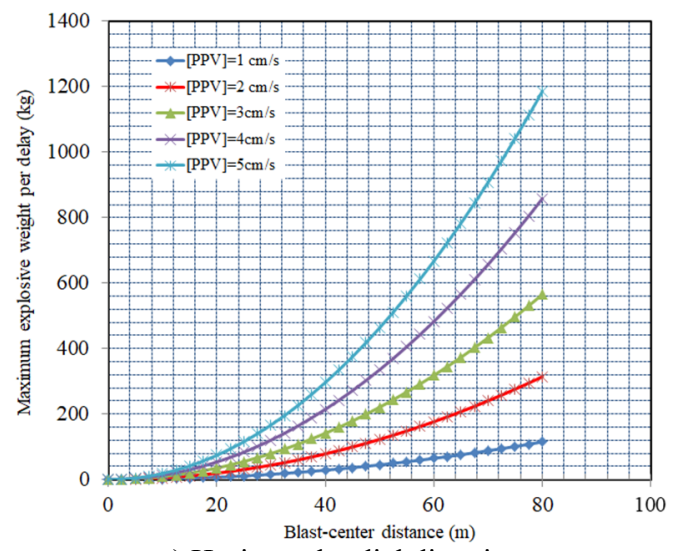

a) Horizontal radial direction

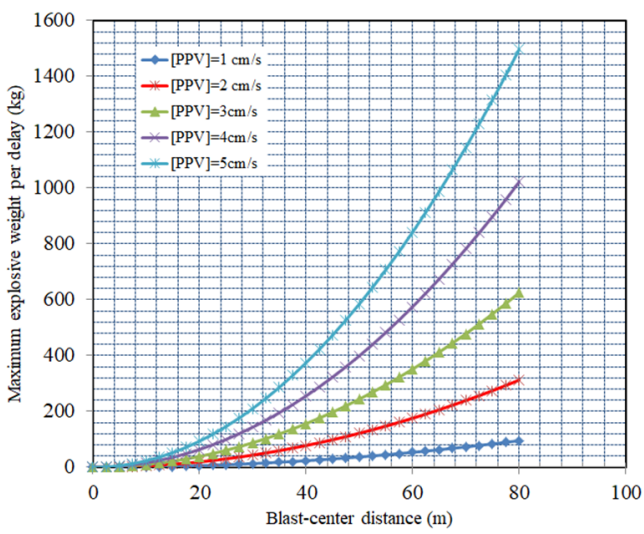

b) Horizontal tangential direction

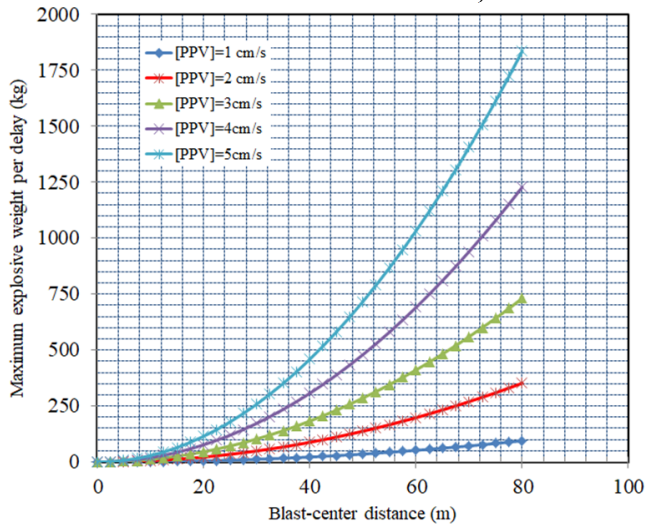

c) Vertical direction

Fig. 16. The relationship between maximum explosive weight per delay and the distance on account of different PPV limit

It is very significant of setting the initiative control standard of particle vibration velocity for new pouring concrete and surrounding rock mass. "Safety regulations for blasting" (GB6722-2014) points out the permitted particle vibration velocity is subject to the maximum value of three mutually perpendicular components in cartesian coordinate of blasting vibration signal and the vibration frequency is the dominant frequency of permitted particle vibration 
velocity. The road corridor belongs to new pouring mass concrete with concrete strength grade of C50 and curing time has been over 28 days at the start of blasting for foundation excavation of road corridor project, as for the measured vibration data, the dominant frequency of the blasting vibration signal is mainly in $10 \mathrm{~Hz}-100 \mathrm{~Hz}$, the safe allowable velocity standard in "Safety regulations for blasting" (GB6722-2014) is 7.0-12.0 cm/s, in order to more safe, the safe allowable peak particle velocity of $5.0 \mathrm{~cm} / \mathrm{s}$ is recommended in this paper. In terms of the safety criterion of peak vibration velocity for the blasting damage of rock mass, the lithologic types of bedrock are slightly weathered calcareous conglomerate, sandy conglomerate and siltstone [60], which should belong to intact rock, Bauer A. [54] point out that there is no fracturing damage of intact rock for blasting excavation when peak particle velocity is under $25.0 \mathrm{~cm} / \mathrm{s}$, as a conservative approach, a PPV of $5.0 \mathrm{~cm} / \mathrm{s}$ was adopted as bedrock safe vibration level for safely completing the road corridor excavation work. Therefore, the initiative control standard of particle vibration velocity for new pouring mass concrete and bedrock in road corridor are both determined to [PPV] $=$ $5.0 \mathrm{~cm} / \mathrm{s}$ according to Table 1 of "Safety regulations for blasting" (GB6722-2014) and expert opinion.

As seen in the Table 5, in terms of the peak particle velocity of 20 groups monitoring data, Due to the phenomenon about field monitoring particle vibration velocity approximate close to initiative control standard of particle vibration velocity is existed, therefore, we should control maximum explosive weight per delay at different distance from the explosion source on the basis of the blast-induced peak particle velocity attenuation law based on Eq. (22-24) and Fig. 16. As shown in Table 8, the maximum explosive weight per delay is controlled by maximum explosive weight per delay of horizontal radial direction. If the distance between road corridor monitoring point and the explosion source is $30 \mathrm{~m}$, the maximum explosive weight per delay can be evaluated to $166.8 \mathrm{~kg}$; that is, it can satisfy the road corridor concrete structure and rock mass safety when the maximum explosive weight per delay is less than $166.8 \mathrm{~kg}$. In order to guarantee safety of damage control for new pouring mass concrete and bedrock in road corridor under blasting load in Xianning Nuclear Power Station, it is essential that we should strictly control maximum explosive weight per delay and total explosive weight based on above calculation results of Table 8 and Fig. 16.

The peak particle velocity and frequency of the total 252 blasting vibration data along the horizontal radial, horizontal tangential and vertical direction were recorded from 84 blasting monitoring points of 19 shots in new pouring mass concrete and bedrock at road corridor were evaluated. The evaluation of damage risk of the blasts on new pouring mass concrete and bedrock is shown in Fig. 17. It was observed in Fig. 17 that the recorded peak particle velocity for nearly all blasts were below allowable limit of PPV $(5 \mathrm{~cm} / \mathrm{s})$ for new pouring mass concrete with curing time over $28 \mathrm{~d}$ and bedrock.

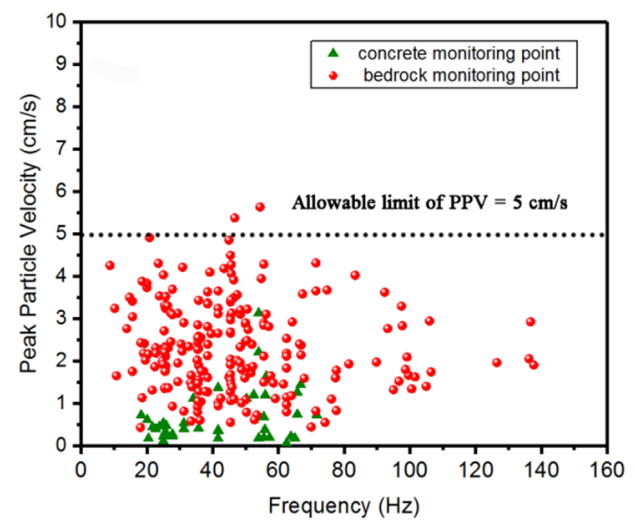

Fig. 17. Evaluation of damage risk of the blasts on new pouring mass concrete and bedrock 
Table 8. The maximum explosive weight per delay calculated by Eq. (22) to Eq. (24)

\begin{tabular}{|c|c|c|c|c|}
\hline \multirow{2}{*}{$\begin{array}{c}\text { Blast radial } \\
\text { distance }(\mathrm{m})\end{array}$} & $\begin{array}{c}\text { Horizontal radial } \\
\text { direction }\end{array}$ & $\begin{array}{c}\text { Horizontal } \\
\text { tangential direction }\end{array}$ & $\begin{array}{c}\text { Vertical } \\
\text { direction }\end{array}$ & $\begin{array}{c}\text { Maximum explosive } \\
\text { weight per delay(kg) }\end{array}$ \\
\cline { 2 - 3 } & $Q_{x}(\mathrm{~kg})$ & $Q_{y}(\mathrm{~kg})$ & $Q_{z}(\mathrm{~kg})$ & 18.5 \\
\hline 10 & 18.5 & 23.4 & 28.7 & 74.1 \\
\hline 20 & 74.1 & 93.5 & 114.7 & 166.8 \\
\hline 30 & 166.8 & 210.4 & 258.1 & 296.5 \\
\hline 40 & 296.5 & 374.1 & 458.9 & 463.3 \\
\hline 50 & 463.3 & 584.5 & 717.0 & 667.1 \\
\hline 60 & 667.1 & 841.7 & 1032.5 & \\
\hline
\end{tabular}

\section{Conclusions}

The peak particle velocity attenuation law are investigated through regression analysis of practical field data by Duvall empirical formula and the time-frequency characteristics was analyzed by wavelet transform and wavelet package decomposition at a road corridor in Xianning Nuclear Power; The dominant frequency distributions of all particle velocity are presented, the relationship between maximum explosive weight per delay and the distance on account of different $\mathrm{PPV}_{\text {limit }}$ are given. In order to reduce the damage extent to the new pouring mass concrete and surrounding rock mass, some initiative control methods for blasting vibration effect is carried out. The main conclusions of the study are drawn as follows:

1) The peak particle velocity attenuation law along the horizontal radial, horizontal tangential and vertical direction is expressed as $\mathrm{PPV}_{\mathrm{x}}=16.0(S D)^{-1.38}, \mathrm{PPV}_{\mathrm{y}}=11.7(S D)^{-1.17}, \mathrm{PPV}_{\mathrm{z}}=$ $10.0(S D)^{-1.11}$, respectively. Based on the above equation, we can effectively present the blasting design about the maximum explosive weight per delay, $Q$, according to the allowable peak particle velocity, $\mathrm{PPV}_{\text {limit }}$, at different distance from the center of explosion, $R$, in terms of requisition of "Safety regulations for blasting" (GB6722-2014) and expert opinion in China, which shows the excellent control effect on blasting damage of the new pouring mass concrete and surrounding rock mass.

2) As for measured data, By analyzing the velocity amplitude and power spectrum density amplitude of wavelet components, it shows the energy of original vibration signal in $250-500 \mathrm{~Hz}$ is very small, the blast energy of original vibration signal is mainly within the frequency below $250 \mathrm{~Hz}$ region and has three sub-band which varies from $10 \mathrm{~Hz}$ to $30 \mathrm{~Hz}$, from $40 \mathrm{~Hz}$ to $70 \mathrm{~Hz}$ and from $75 \mathrm{~Hz}$ to $125 \mathrm{~Hz}$, respectively, in which the main energy concentrates in the range of $40 \mathrm{~Hz}$ to $70 \mathrm{~Hz}$, and the energy in the range of $10 \mathrm{~Hz}$ to $30 \mathrm{~Hz}$ and $75 \mathrm{~Hz}$ to $125 \mathrm{~Hz}$ is relatively weak. Wavelet packet analysis indicates the energy of the signal in $0-125 \mathrm{~Hz}$ accounts for $94.25 \%$ of the total signal and the energy percentage between the $11.72-31.25 \mathrm{~Hz}, 39.06-70.31 \mathrm{~Hz}$ and $74.22-125 \mathrm{~Hz}$ is $22.15 \%, 33.73 \%$ and $28.40 \%$, respectively.

3) The initiative control for blasting vibration effect is mainly by controlling maximum explosive weight per delay and total explosive weight, meanwhile, adopting decoupling charge and millisecond delay blasting technology; in which the initiative control standard of particle vibration velocity for new pouring mass concrete and bedrock in road corridor both is determined to $[\mathrm{PPV}]=5.0 \mathrm{~cm} / \mathrm{s}$, the radial uncoupling coefficient of about 2.81 or 3.59 , four multiple section of non-electric shock tube delay detonator is usually used with millisecond connector. the recorded peak particle velocity for nearly all blasts were below allowable limit of PPV for new pouring mass concrete with curing time over $28 \mathrm{~d}$ and bedrock.

\section{Acknowledgments}

The study was supported by the Key Program of National Natural Science Foundation of China (Grant No. 51439008), National Natural Science Foundation of China (Grant Nos. 41572307 and 51779248), and The Program of Hunan Province Education Department of China under (Grant 
No. 19C0870). The authors are also very grateful to the editors and anonymous reviewers for valuable suggestions which have improved the quality of this paper.

\section{References}

[1] Wang Z. W., Li X. B., Peng K., et al. Impact of blasting parameters on vibration signal spectrum: Determination and statistical evidence. Tunnelling and Underground Space Technology, Vol. 48, Issue 1, 2015, p. 94-100.

[2] Torres V. F., Silveira L. G., Lopes P. F., et al. Assessing and controlling of bench blasting-induced vibrations to minimize impacts to a neighboring community. Journal of Cleaner Production, Vol. 187, Issue 1, 2018, p. 514-524.

[3] Yan Y., Hou X. M., Fei H. L. Review of predicting the blast-induced ground vibrations to reduce impacts on ambient urban communities. Journal of Cleaner Production, Vol. 260, Issue 1, 2020, p. 1-21.

[4] Ainalis D., Ducarne L., Kaufmann O., et al. Improved analysis of ground vibrations produced by man-made sources. Science of The Total Environment, Vol. 616, Issue 1, 2018, p. 517-530.

[5] Murmu S., Maheshwari P., Verma H. K. Empirical and probabilistic analysis of blast-induced ground vibrations. International Journal of Rock Mechanics and Mining Sciences, Vol. 103, Issue 1, 2018, p. 267-274.

[6] Singh P. K., Roy M. P. Damage to surface structures due to blast vibration. International Journal of Rock Mechanics and Mining Sciences, Vol. 47, Issue 6, 2010, p. 949-961.

[7] Zhang C. S., Hu F., Zou S. Effects of blast induced vibrations on the fresh concrete lining of a shaft. Tunnelling and Underground Space Technology, Vol. 20, Issue 4, 2005, p. 356-361.

[8] Sun X. M., Wang J. Y. Evaluation of blasting vibration effects on buildings. Blasting, Vol. 25, Issue 2, 2008, p. 73-76.

[9] Deng T., Jin Y. P., Wu P. G., et al. Highway tunnel blasting vibrations and cracking of adjacent residential houses. Modern Tunnelling Technology, Vol. 55, Issue 3, 2018, p. 69-75.

[10] Jiang D. Y., Hou Y. B., Ren S., et al. Study on the influence of urban large-span tunnel blasting on ground buildings. China Safety Science Journal, Vol. 18, Issue 7, 2008, p. 99-104.

[11] Li H. B., Xia X., L. J. C., et al. Rock damage control in bedrock blasting excavation for a nuclear power plant. International Journal of Rock Mechanics and Mining Sciences, Vol. 48, Issue 2, 2011, p. 210-218.

[12] Zeng Y. Q., Li H. B., Xia X., et al. Blast-induced rock damage control in Fangchenggang nuclear power station, China. Journal of Rock Mechanics and Geotechnical Engineering, Vol. 10, Issue 5, 2018, p. 914-923.

[13] Li X. F., Li H. B., Zhang G. K. Damage assessment and blast vibrations controlling considering rock properties of underwater blasting. International Journal of Rock Mechanics and Mining Sciences, Vol. 121, Issue 1, 2019, p. 104045.

[14] Nateghi R. Prediction of ground vibration level induced by blasting at different rock units. International Journal of Rock Mechanics and Mining Sciences, Vol. 48, Issue 6, 2011, p. 899-908.

[15] Nateghi R. Evaluation of blast induced ground vibration for minimizing negative effects on surrounding structures. Soil Dynamics and Earthquake Engineering, Vol. 43, Issue 1, 2012, p. $133-138$.

[16] Li P., Lu W. B., Wu X. X., et al. Spectral prediction and control of blast vibrations during the excavation of high dam abutment slopes with millisecond-delay blasting. Soil Dynamics and Earthquake Engineering, Vol. 94, Issue 1, 2017, p. 116-124.

[17] Qiu X. Y., Shi X. Z., Gou Y. G., et al. Short-delay blasting with single free surface: results of experimental tests. Tunnelling and Underground Space Technology, Vol. 74, Issue 1, 2018, p. 119-130.

[18] Faramarzi F., Farsangi M. A., Mansouri H. Simultaneous investigation of blast induced ground vibration and airblast effects on safety level of structures and human in surface blasting. International Journal of Mining Science and Technology, Vol. 24, Issue 5, 2014, p. 663-669.

[19] Ak H., Konuk A. The effect of discontinuity frequency on ground vibrations produced from bench blasting: A case study. Soil Dynamics and Earthquake Engineering, Vol. 28, Issue 9, 2008, p. 686-694.

[20] Ak H., Iphar M., Yavuz M., et al. Evaluation of ground vibration effect of blasting operations in a magnesite mine. Soil Dynamics and Earthquake Engineering, Vol. 29, Issue 4, 2009, p. 669-676. 
[21] Simangunsong G. M., Wahyudi S. Effect of bedding plane on prediction blast-induced ground vibration in open pit coal mines. International Journal of Rock Mechanics and Mining Sciences, Vol. 79, Issue 1, 2015, p. 1-8.

[22] Shin J. H., Moon H. G., Chae S. E. Effect of blast-induced vibration on existing tunnels in soft rocks. Tunnelling and Underground Space Technology, Vol. 26, Issue 1, 2011, p. 51-61.

[23] Yu H. T., Yuan Y., Yu G. X., et al. Evaluation of influence of vibrations generated by blasting construction on an existing tunnel in soft soils. Tunnelling and Underground Space Technology, Vol. 43, Issue 1, 2014, p. 59-66.

[24] Xia X., Li H. B., Li J. C., et al. A case study on rock damage prediction and control method for underground tunnels subjected to adjacent excavation blasting. Tunnelling and Underground Space Technology, Vol. 35, Issue 1, 2013, p. 1-7.

[25] Gou Y. G., Shi X. Z., Zhou J., et al. Attenuation assessment of blast-induced vibrations derived from an underground mine. International Journal of Rock Mechanics and Mining Sciences, Vol. 127, Issue 1, 2020, p. 104220.

[26] Singh P. K., Roy M. P., Paswan R. K., et al. Blast vibration effects in an underground mine caused by open-pit mining. International Journal of Rock Mechanics and Mining Sciences, Vol. 80, Issue 1, 2015, p. 79-88.

[27] Roy M. P., Singh P. K., Sarim M. D., et al. Blast design and vibration control at an underground metal mine for the safety of surface structures. International Journal of Rock Mechanics and Mining Sciences, Vol. 83, Issue 1, 2016, p. 107-115.

[28] Jiang N., Zhou C. B., Lu S. W., et al. Propagation and prediction of blasting vibration on slope in an open pit during underground mining. Tunnelling and Underground Space Technology, Vol. 70, Issue 1, 2017, p. 409-421.

[29] Li X. B., Zhang Y. P., Liu Z. X., et al. Wavelet analysis and Hilbert-Huang transform of blasting vibration signal. Explosion and Shock Waves, Vol. 25, Issue 6, 2005, p. 528-535.

[30] Xu G. Y., Zhong G. S., Xiong Z. M. Study and application of energy analysis method for blasting seismic safety based on wavelet transform. Chinese Journal of Geotechnical Engineering, Vol. 28, Issue 1, 2006, p. 24-28.

[31] Zhong G. S., Li J., Zhao K. Structural safety criteria for blasting vibration based on wavelet packet energy spectra. Mining Science and Technology (China), Vol. 21, Issue 1, 2011, p. 35-40.

[32] Zhong G. S., Ao L. P., Zhao K. Influence of explosion parameters on wavelet packet frequency band energy distribution of blast vibration. Journal of Central South University, Vol. 19, Issue 1, 2012, p. 2674-2680.

[33] Zhao M. S., Zhang J. H., Yi C. P. Time-frequency characteristics of blasting vibration signals measured in milliseconds. Mining Science and Technology (china), Vol. 21, Issue 3, 2011, p. 349-352.

[34] Han B., Ma Q. Y. Wavelet packet analysis of energy distribution features of blasting vibration signals in coal mine rock roadway. China Mining Magazine, Vol. 22, Issue 6, 2013, p. 110-113.

[35] Shi X. Z., Qiu X. Y., Zhou J., et al. Application of Hilbert-Huang transform based delay time identification in optimization of short millisecond blasting. Transactions of Nonferrous Metals Society of China, Vol. 26, Issue 7, 2016, p. 1965-1974.

[36] Li X. L., Li Z. H., Wang E. Y., et al. Analysis of natural mineral earthquake and blast based on Hilbert-Huang transform (HHT). Journal of Applied Geophysics, Vol. 128, Issue 1, 2016, p. 79-86.

[37] Lu W. B., Lai S. X., Zhu C. Y., et al. Safety standards of blast vibrations adopted in rock base excavation of three gorge project. Explosion and Shock Waves, Vol. 21, Issue 1, 2001, p. 67-71.

[38] Lu W. B., Li H. B., Chen M., et al. Safety criteria of blasting vibration in hydropower engineering and several key problems in their application. Chinese Journal of Rock Mechanics and Engineering, Vol. 28, Issue 8, 2009, p. 1513-1520.

[39] Lu S. H., Zhou C. B., Jiang N., et al. Effect of excavation blasting in an under-cross tunnel on airport runway. Geotechnical and Geological Engineering, Vol. 33, Issue 3, 2015, p. 973-981.

[40] Li X. B., Ling T. H., Zhang Y. P. Analysis of Blast Vibration Signals Theories and Methods. Science Press, Beijing, 2009.

[41] Duvall W. I., Fogelson D. E. Review of Criteria for Estimating Damage to Residences from Blasting Vibration. Report No. R.I. 5968, United States Bureau of Mines, Washington, 1962.

[42] Langefors U., Kihlstrom B. The Modern Technique of Rock Blasting. John Wiley and Sons, New York, 1963.

[43] IS 6922. Criteria for Safety and Design of Structures Subject to Underground Blast. Bureau of Indian Standards (BIS), New Delhi, India, 1973. 
[44] Pal Roy P. Vibration control in an opencast mine based on improved blast vibration predictors. Mining Science and Technology, Vol. 12, Issue 2, 1991, p. 157-165.

[45] GB6722-2014. Safety Regulations for Blasting. Standards Press of China, Beijing, 2014, (in Chinese).

[46] Kumar R., Choudhury D., Bhargava K. Determination of blast-induced ground vibration equations for rocks using mechanical and geological properties. Journal of Rock Mechanics and Geotechnical Engineering, Vol. 8, Issue 3, 2016, p. 341-349.

[47] Blair D. P. Blast vibration dependence on charge length, velocity of detonation and layered media. International Journal of Rock Mechanics and Mining Sciences, Vol. 65, Issue 1, 2014, p. 29-39.

[48] Tripathy G. R., Shirke R. R., Kudale M. D. Safety of engineered structures against blast vibrations: A case study. Journal of Rock Mechanics and Geotechnical Engineering, Vol. 8, Issue 2, 2016, p. 248-255.

[49] Zhang D. F. Wavelet analysis. China Machine Press, Beijing, 2011.

[50] Pei L., Liu J., Guinness R., et al. Using LS-SVM Based Motion Recognition for Smartphone Indoor Wireless Positioning. Sensors, Vol. 12, Issue 5, 2012, p. 6155-6175.

[51] Wang X. G., Yu Y. L. On several problems of safety criterion of blasting vibration. Engineering Blasting, Vol. 7, Issue 2, 2001, p. 88-92.

[52] Zhang J. C. Vibration characteristics of blasting in bed rock mass at Three Gorges project. Explosion and Shock Waves, Vol. 21, Issue 2, 2001, p. 131-137.

[53] Huang Z. P., Song Y. L. Effect and control of the blast for the remnant rock mass. Journal of Wuhan Automotive Polytechnic University, Vol. 21, Issue 6, 1999, p. 90-94.

[54] Bauer A., Calder P. N. Open pit and blast seminar. Mining Engineering Department, Kingston, Ontario, Canada, 1978.

[55] Mojtabai N., Beattie S. G. Empirical approach to prediction of damage in bench blasting. Transactions of the Institution of Mining and Metallurgy, Vol. 105, Issue 1, 1996, p. 75-80.

[56] Wang X. F. Selection and Optimization of Wavelet Base. Journal of Zhuzhou Institute of Technology, Vol. 17, Issue 5, 2003, p. 33-35.

[57] Wang H. B. Study on Roadway Stability and Control of Blasting Seismic Effect in Coal Mine. Ph.D. Thesis, Anhui University of Science and Technology. Huainan, China, 2012.

[58] Zong Q., Wang H. B., Zhou S. B. Research on monitoring and controlling techniques considering effects of seismic shock. Chinese Journal of Rock Mechanics and Engineering, Vol. 27, Issue 5, 2008, p. $938-945$.

[59] Siskind D. E., Stagg M. S., Kopp J. W., Dowding C. H. Structure response and damage produced by ground-vibration from surface mine blasting. Report No. RI 8507, Washington, United States Bureau of Mines; 1980.

[60] Li W. Q. Geotechnical characteristics of the upper cretaceous -tertiary at dafan nuclear power plant of tongshan county in hubei. Resources and Environment Engineering, Vol. 20, Issue 1, 2006, p. 32-35.

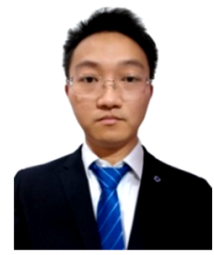

Yongqing Zeng received his M.S. degree from Anhui University of Science and Technology, Huainan, China, in 2016, and received the Ph.D. degree from Institute of Rock and Soil Mechanics, Chinese Academy of Sciences, Wuhan, China, in 2019. His research interests are mainly on rock dynamic, the safety evaluation of geotechnical engineering subjected to dynamic loads. Yongqing Zeng has worked as a Lecturer in Hunan Institute of Science and Technology. He authored or co-authored 15 journal papers and 4 international conference papers to date. Yongqing Zeng performed the formal analysis and wrote the original draft preparation.

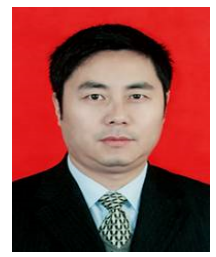

Haibo Li received the Ph.D. degree from Institute of Rock and Soil Mechanics, Chinese Academy of Sciences, Wuhan, China, in 1999. Li is the distinguished Professor of State Key Laboratory of Geomechanics and Geotechnical Engineering, Institute of Rock and Soil Mechanics, Chinese Academy of Sciences, Wuhan, China. His research interests cover rock dynamics and earthquake engineering. He is the author of 2 books and has published more than 200 technical papers. Haibo Li contributed to conceptualization, funding acquisition and data curation of the study. 


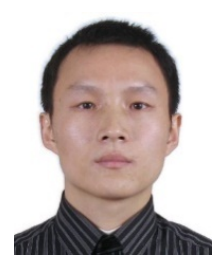

Xiang Xia received the Ph.D. degree from Institute of Rock and Soil Mechanics, Chinese Academy of Sciences, Wuhan, China, in 2006. He is now a Associate Professor in Institute of Rock and Soil Mechanics, China. His research interests are mainly on rock dynamic, the safety evaluation of geotechnical engineering subjected to dynamic loads. He is an author of more than 25 scientific papers with over 10 indexed in major scientific databases. Xiang Xia contributed significantly to investigation and methodology.

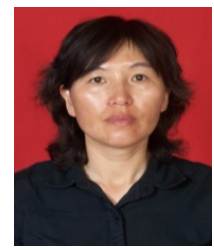

Junru Li received hers M.S. degree from Huazhong University of Science and Technology, Wuhan, China, in 2002. She is now a Associate Professor in Institute of Rock and Soil Mechanics, China. Hers research interests are mainly on rock dynamic, monitoring and analysis of vibration effects subjected to dynamic loads. She is an author of more than 20 scientific papers with over 8 indexed in major scientific databases. Junru Li helped perform review and editing with constructive discussions.

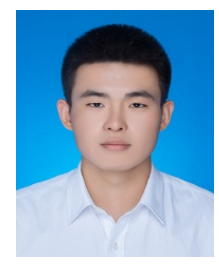

Zhiwen Li received his bachelor's degree from Jiangxi University of Science and Technology, Ganzhou, China, in 2015. In the same year, Li started his Master program in University of Chinese Academy of Sciences, Beijing, China and State Key Laboratory of Geomechanics and Geotechnical Engineering, Institute of Rock and Soil Mechanics, Chinese Academy of Sciences, Wuhan, China. Zhiwen Li's Master program focuses on rock dynamic mechanics, for example effect of topography on propagation of blasting waves. Zhiwen $\mathrm{Li}$ has authored or co-authored 3 journal papers and 1 international conference papers to date. Zhiwen Li helped perform review and editing with constructive discussions.

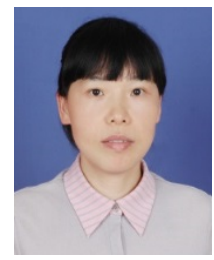

Xiaohong Liu received the Ph.D. degree from Central South Univesrtiy, Changsha, China, in 2011. She is the Professor of College of Civil Engineering and Architecture, Hunan Institute of Science and Technology, Yueyang, China. Her research interests cover excavation engineering and earth pressure and non-contact testing of foundation deformation. She has published more than 30 technical papers. Xiaohong Liu contributed significantly to investigation and methodology. 